\title{
Gravity Wave Breaking Associated with Mesospheric Inversion Layers as Measured by the Ship-Borne BEM Monge Lidar and ICON-MIGHTI
}

\author{
Robin Wing 1,2,3,* (D), Milena Martic ${ }^{1,2}$, Colin Triplett ${ }^{4}\left(\mathbb{D}\right.$, Alain Hauchecorne ${ }^{1,2}$, Jacques Porteneuve ${ }^{1,2}$, \\ Philippe Keckhut ${ }^{1}$, Yann Courcoux ${ }^{5}$, Laurent Yung ${ }^{6}$, Patrick Retailleau ${ }^{6}$ and Dorothee Cocuron ${ }^{7}$
}

\section{check for}

updates

Citation: Wing, R.; Martic, M.; Triplett, C.; Hauchecorne, A.; Porteneuve, J.; Keckhut, P.; Courcoux, Y.; Yung, L.; Retailleau, P.; Cocuron, D. Gravity Wave Breaking Associated with Mesospheric Inversion Layers as Measured by the Ship-Borne BEM Monge Lidar and ICON-MIGHT. Atmosphere 2021, 12, 1386. https:// doi.org/10.3390/atmos12111386

Academic Editor: Paul D. Williams

Received: 14 September 2021

Accepted: 18 October 2021

Published: 22 October 2021

Publisher's Note: MDPI stays neutral with regard to jurisdictional claims in published maps and institutional affiliations.

Copyright: (c) 2021 by the authors. Licensee MDPI, Basel, Switzerland. This article is an open access article distributed under the terms and conditions of the Creative Commons Attribution (CC BY) license (https:// creativecommons.org/licenses/by/ $4.0 /)$.
1 Laboratoire Atmosphères, Milieux, Observations Spatiales (LATMOS), Institut Pierre Simon Laplace (IPSL), UVSQ Université Paris-Saclay, Sorbonne Université, CNRS, 78280 Guyancourt, France; Milena.Martic@latmos.ipsl.fr (M.M.); Alain.Hauchecorne@latmos.ipsl.fr (A.H.); Jacques.Porteneuve@latmos.ipsl.fr (J.P.); Philippe.Keckhut@latmos.ipsl.fr (P.K.)

2 Gordien Strato, 11 Boulevard d'Alembert, 78280 Guyancourt, France

3 Leibniz Institute for Atmospheric Physics, Schloßstraße 6, 18225 Kühlungsborn, Germany

4 Space Sciences Laboratory, University of California Berkeley, Berkeley, CA 94720, USA; triplett@berkeley.edu

5 Direction Générale de l'Armement DGA, 60 bd Gén Martial Valin, 75015 Paris, France; yann.courcoux@intradef.gouv.fr

6 Direction Générale pour 1'Armement, Direction des Essais, DGA-Essais de Missiles, BEM Monge, BCRM Brest, C.C. 51, CEDEX 9, F-29240 Brest, France; laurent.yung@intradef.gouv.fr (L.Y.); patrick.retailleau@intradef.gouv.fr (P.R.)

7 Direction Générale pour l'Armement, Essais de Missiles site Landes, 40115 Biscarrosse Air, France; dorothee.cocuron@intradef.gouv.fr

* Correspondence: wing@iap-kborn.de

Abstract: During a recent 2020 campaign, the Rayleigh lidar aboard the Bâtiment d'Essais et de Mesures (BEM) Monge conducted high-resolution temperature measurements of the upper Mesosphere and Lower Thermosphere (MLT). These measurements were used to conduct the first validation of ICON-MIGHTI temperatures by Rayleigh lidar. A double Mesospheric Inversion Layer (MIL) as well as shorter-period gravity waves was observed. Zonal and meridional wind speeds were obtained from locally launched radiosondes and the newly launched ICON satellite as well as from the European Centre for Medium-Range Weather Forecasts (ECMWF-ERA5) reanalysis. These three datasets allowed us to see the evolution of the winds in response to the forcing from the MIL and gravity waves. The wavelet analysis of a case study suggests that the wave energy was dissipated in small, intense, transient instabilities about a given wavenumber in addition to via a broad spectrum of breaking waves. This article will also detail the recent hardware advances of the Monge lidar that have allowed for the measurement of MILs and gravity waves at a resolution of 5 min with an effective vertical resolution of $926 \mathrm{~m}$.

Keywords: Rayleigh lidar; middle atmosphere; temperature; density; gravity waves; Mesospheric Inversion Layer; instability

\section{Introduction}

The principal objective of the Bâtiment d'Essais et de Mesures (BEM) Monge Lidar (also referred to by the anglicized abbreviation Advanced Test Range Ship Monge (ATRSM) Lidar, or more simply as Monge Lidar) is to provide temperature and density profiles with as much accuracy and precision as possible at a given time and location during the reentry phase of a ballistic missile flight [1]. As a secondary objective, we can use these high-resolution measurements to study middle atmospheric dynamics. 


\subsection{Gravity Waves}

Gravity waves (GWs) and solar tides are the main sources of energy and momentum that drive mesospheric dynamics and circulation. GWs are perturbations in atmospheric density, temperature, and wind speed that are primarily generated from tropospheric sources such as jet streams, orography, convection, and weather systems [2]. The linear theory of GWs, also referred to as internal atmospheric buoyancy waves, was laid out by Hines [3] and expanded on by the authors Lindzen [4], Holton [5], Fritts [6], Garcia and Solomon [7] (among others). Secondary GWs can also be generated through non-linear processes when a primary GW breaks at high altitudes [8]. These small-scale secondary GWs can be produced locally or can be ducted (internally reflected through a waveguide created by vertical gradients in temperature or wind speed) over many hundreds of kilometers [9]. Gravity wave perturbations to the mean atmospheric temperature profile generally have periods of minutes to hours and grow in amplitude as they propagate upwards in the atmosphere, achieving vertical wavelengths of tens of kilometers and horizontal wavelengths of up to a few hundred kilometers. When these waves eventually break in the upper Mesosphere and Lower Thermosphere (MLT) they deposit energy and momentum into the mean state of the atmosphere. This deposition of energy can modify the local temperature structure and wind fields and can have an important impact on the flight conditions of ballistic vehicles and space shuttle re-entry $[1,10]$.

The study of GWs using both Rayleigh and resonance lidar techniques has been extensively investigated by multiple authors over the last 40 years [11-21] (and many others) due to their vital importance in global circulation. However, despite the depth of available literature, there is little written about simultaneous measurements of high-frequency GWdriven temperature, density, and wind fluctuation profiles covering the region from the upper troposphere to the MLT made at very high temporal and spatial resolutions.

In this study, we were interested in exploiting the capabilities of the newly enhanced Monge lidar to investigate the smallest, high-frequency waves, which are usually filtered out in studies that use nightly mean lidar temperatures or long integration times. Considering the GW dispersion relation Equation (1) for waves traveling with the background wind field (Lagrangian reference frame) can help us to estimate what kind of waves we can observe using the Monge lidar and how these waves might affect the MLT region. In the case of short-period gravity waves, we can follow the general derivation of Fritts and Alexander [2] but ignore the Coriolis parameter, $f^{2}$, and simplify the dispersion equation to Equation (2), where we have combined the zonal wavenumber, $k^{2}$, and meridional wavenumber, $l^{2}$, into a horizontal wavenumber, $k_{x}^{2}$. In Equation (1) and Equation (2), $N^{2}$ represents the Brunt-Väisälä frequency; $\omega^{2}$, the intrinsic frequency of the GW; and $H$, the atmospheric scale height.

$$
\begin{gathered}
\omega^{2}=\left(\frac{N^{2}\left(k^{2}+l^{2}\right)+f^{2}\left(m^{2}+\frac{1}{4 H^{2}}\right)}{k^{2}+l^{2}+m^{2}+\frac{1}{4 H^{2}}}\right) \\
\omega^{2}=\left(\frac{N^{2} k_{x}^{2}}{k_{x}^{2}+m^{2}+\frac{1}{4 H^{2}}}\right)
\end{gathered}
$$

All sky CCD cameras measuring infrared emissions from the $\mathrm{OH}$ layer have previously shown small-scale GW "ripples" such as Isler et al. [9], Taylor et al. [22] and, more recently, Sedlak et al. [23]. These events have horizontal scales between 5 and $15 \mathrm{~km}$, and periods approaching the local Brunt-Väisälä frequency (approx. $5 \mathrm{~min}$ ), and are propagating in the MLT, where the local scale height is on the order of 5 to $6 \mathrm{~km}$. These wave scales give us an idea of the size of the small-scale wave events or instabilities that the lidar might detect in the MLT.

We can isolate the vertical wavenumber, $m$, and vertical wavelength, $\lambda_{z}=\frac{2 \pi}{m}$, and re-express Equation (2) as Equation (3). Using lower-limit assumptions for the horizontal wavenumber $k_{x} \approx \frac{2 \pi}{5000 \mathrm{~m}}$, a Brunt-Väisälä frequency of $N^{2} \approx \frac{1}{300 \mathrm{~s}^{2}}$, intrinsic wave frequency 
$\omega^{2} \approx \frac{1}{1800 \mathrm{~s}^{2}}$, and a scale height, $H$, of $5500 \mathrm{~m}$, we can estimate the order of magnitude for the vertical wavelength of a short-period GW, which could be measured by the Monge as $\lambda_{z} \approx 845 \mathrm{~m}$.

$$
m^{2}=k_{x}^{2}\left(\frac{N^{2}}{\omega^{2}}-1\right)-\frac{1}{4 H^{2}}
$$

These small vertical wavelengths could be permitted at lower altitudes, but we expect them to be damped by viscosity through increasing Reynolds numbers as they approach $110 \mathrm{~km}$ in the MLT [24,25]. Further complexities arise, as we cannot assume the waves measured by the lidar are locally generated, are freely propagating, and are not interacting with long-period waves. Small-scale GWs (periods less than an hour) and horizontal scales $\left(\sim 10^{2}-10^{3} \mathrm{~km}\right)$ can be easily ducted into the lidar field of view from many hundreds of kilometers away from their source.

\subsection{Mesospheric Inversion Layers}

As previously stated, when a wave breaks in the upper atmosphere, it will deposit its energy and momentum into the surrounding atmosphere. When this influx of energy occurs in the mesosphere, it can cause turbulence and sufficient local heating to cause the local temperature gradient to change sign [11,26]. An inversion layer of this kind is commonly referred to as a Mesospheric Inversion Layer (MIL). The bottom side of the MIL (positive temperature gradient) can be characterized as a region with increased static stability, $N^{2}$, as given in Equation (4), where $g(z)$ is the local gravitational acceleration, $C_{p}$ is the specific heat at constant pressure, and $T(z)$ is the lidar temperature profile. While positive, this quantity, $N^{2}$, signifies regions of the atmosphere that are stably stratified and unlikely to support large-scale vertical mixing and turbulence. By contrast, the top side of a MIL has a negative temperature lapse rate and can support the generation of turbulence.

$$
N^{2}(z)=\frac{g(z)}{T(z)}\left(\frac{d T}{d z}+\frac{g(z)}{C_{p}}\right)
$$

MILs were first detected by Schmidlin [27] near $75 \mathrm{~km}$ in rocket data and were noted to have vertical extents of several kilometers and temperature enhancements of tens of kelvin with respect to the expected positive mesospheric temperature lapse rate. The first lidar measurements of MILs were made in Hauchecorne et al. [11] and showed a "lower MIL" near $75 \mathrm{~km}$ and an "upper MIL" near $90 \mathrm{~km}$. The review article by Meriwether and Gardner [26] notes that these "double MILs" are common. The lower MILs that form between 65 and $80 \mathrm{~km}$ are likely the result of planetary waves and GWs breaking through interactions with the winds $[11,28]$, while the upper MILs, between 85 and $100 \mathrm{~km}$, are likely driven by GWs interacting with winds and by non-linear effects such as wave-wave interactions [26]. Recently, lidar and SABER (Sounding of the Atmosphere using Broadband Emission Radiometry) measurements onboard the TIMED (Thermosphere, Ionosphere, Mesosphere Energetics and Dynamics) satellite [29] have suggested the presence of a third MIL located above $95 \mathrm{~km}$, which is primarily driven by chemical heating by atomic oxygen [30].

MILs at equatorial latitudes have previously been studied using rockets [31], SABER [32,33], and Rayleigh lidar [34]. It has been shown that, at lower latitudes, MILs can exhibit larger maximum amplitudes (up to $\sim 36 \mathrm{~K}$ ) [33] when compared to MILs at midlatitudes (12-32 K) [34]. In addition, the seasonal occurrence of MILs shows semi-annual maxima near the equinoxes [33], which contrasts the annual cycle seen at mid-latitudes [35].

\subsection{Wind-Wave Interactions}

Wind-wave interactions can cause a traveling GW or long-period wave to lose energy when the phase speed of the wave exceeds the background wind speed (zero wind from the perspective of a traveling wave) [36]. We expect that the majority of the GW energy is dissipated in the region between $85 \mathrm{~km}$ (mesopause) and approx. 105-110 km (the so-called turbopause above which the molecular viscosity is the dominant dispersive term). We 
also expect that the longer-intrinsic-wavelength GWs encounter a zero-wind line at lower altitudes than shorter-intrinsic-wavelength GWs, which can propagate to higher altitudes.

During summer months at northern tropical latitudes, the mean zonal wind is eastward throughout most of the middle atmosphere and reverses in the MLT above $80 \mathrm{~km}$ [37]. In general, we can suppose an ideal case for a wave traveling westward in the stratosphere and mesosphere, which will propagate freely in the westerly wind and will be filtered by the easterly wind in the MLT [38]. Adding complexity to this model, migrating and non-migrating tides will modify the local winds and raise or lower the altitude at which a GW encounters its zero-wind line.

The mean meridional winds are much weaker than the zonal winds. They are near zero throughout most of the troposphere and stratosphere, become northerly (blowing north to south) in the mesosphere, and reverse again (south to north) in the thermosphere. Given that a component of our horizontal wavenumber, $k_{x}$, is meridional, there should be similar GW and planetary wave filtering, albeit to a lesser extent, as exists for the zonal wave components.

\subsection{Large-Scale Waves}

Planetary waves, Kelvin waves, and tides larger than our nightly lidar datasets (four to nine hours) could also have a significant influence [28,39]. Unfortunately, we cannot replicate the 10-day continuous lidar study conducted by Baumgarten et al. [40], which was able to assess the contribution of longer-period waves. The Monge lidar does not yet have the capacity for daylight observations. In this article, we will restrict our focus to smaller-scale waves over the course of a few consecutive nights.

\section{Instruments and Data}

\subsection{Monge Lidar and Experimental Improvements}

Originally designed at the end of the 1980s [1], the Monge lidar was first upgraded in 2005 and is now in its second program of extensive renovations and improvements. The renovation period started in 2019 Wing et al. [41] and is scheduled for completion and final testing in 2021. However, even when operating the lidar in a non-optimized state, we are able to achieve our operational goals and provide an interesting case study that explores MLT geophysics at a higher temporal and vertical resolution than has previously been attempted with any Rayleigh lidar system. Further details regarding the evolution of the Monge lidar (previously aboard the Poincaré) and the use of Raman channels for calculating temperatures can be found in Keckhut et al. [42,43], Faduilhe et al. [44], Hauchecorne et al. [45].

In the previous Monge article [41], we provided an estimate of the Signal-to-Noise Ratio (SNR) of the Monge lidar at $60 \mathrm{~km}$ before and after the replacement of the photomultiplier tubes (PMT) and counting electronics (Licel) in 2018. Since that publication, we have replaced all nine $50 \mathrm{~cm}$ transmission and receiver telescopes, have introduced an autoalignment system, and have performed the installation of a vibrational Raman temperature channel at $608 \mathrm{~nm}$. The Raman temperatures are used to correct the aerosol-induced cold bias at the low-gain Rayleigh temperatures, which was noted in 2020. The increased signals due to aerosols in the Rayleigh channel correspond to "higher density" and, hence, a cold bias in the Rayleigh temperature. The vibrational Raman at $607 \mathrm{~nm}$ is less affected by aerosols and more closely follows the molecular profile. The Raman signals go up to $70 \mathrm{~km}$. We combine photon count profiles for the Rayleigh and Raman channels. The region of transition from Rayleigh to Raman depends on the relative signal strength and is generally $30-35 \mathrm{~km}$.

In Figure 1, we show the updated time evolution of the SNR for the Monge lidar during the recent renovations. For maintaining long-term stability and capabilities and detecting any potential drift due to instrumental degradation, the SNR needs to be monitored. It is important to note that these SNR values are now calculated at 70-75 km instead of 60-65 km (as was previously published in Wing et al. [41]) to accommodate the larger signals. We can see that the average improvement from replacing the PMTs and counting 
electronics is on the order of $436 \%$, and the subsequent improvement due to re-finished new telescopes and approximate auto-alignment is a further $52 \%$. In total, the average signal has improved by $716 \%$ since 2018 . We expect some additional signal gain once the auto-alignment system is completely calibrated.

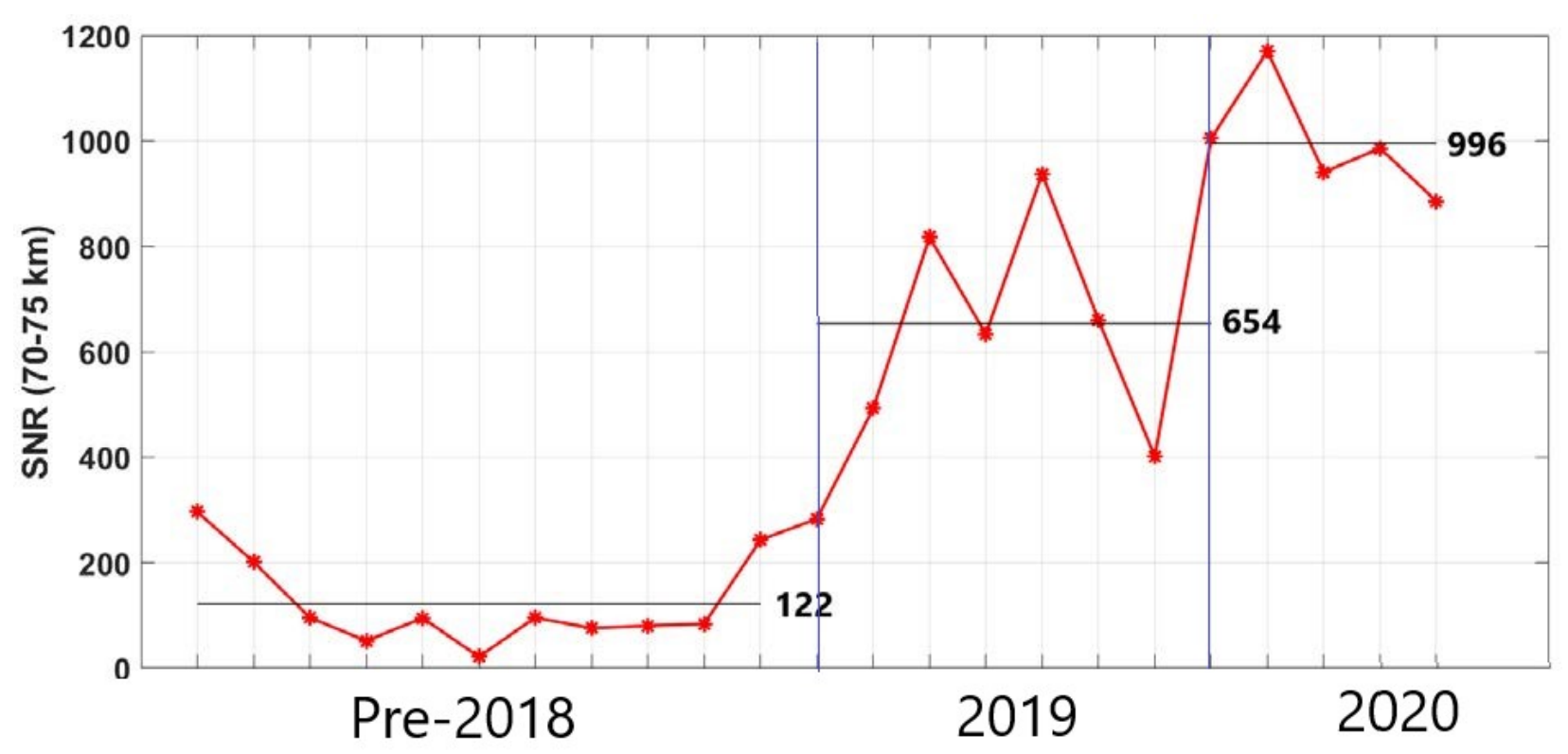

Figure 1. Monge lidar SNR from 70 to $75 \mathrm{~km}$ for selected nights. The improvements in 2019 correspond to the replacement of the PMTs and Licel; the improvements in 2020 correspond to the replacement of all nine lidar mirrors.

Previously, the Monge lidar suffered from an aerosol-induced cold bias below $35 \mathrm{~km}$, and it was decided to implement a vibrational Raman channel at $608 \mathrm{~nm}$ to reduce the severity of this problem and extend our lidar measurements down to the altitude where the overlap correction becomes important $(\sim 15 \mathrm{~km})$. In Figure 2, we have shown two examples of the nightly average Raman lidar signal compared with ship-born radiosonde measurements made throughout the night. In the left-hand panel, we can see that there is good agreement between the lidar and the sondes when reproducing the average temperature profile as well as the small-scale structures. There is a small layer near $33 \mathrm{~km}$, which is detected by both techniques. We can also see that, below 15 or $16 \mathrm{~km}$, the overlap function becomes increasingly important in the lidar signal as the green curve gains a warm bias. We have chosen to truncate the lidar profile instead of attempting to calculate the overlap correction (for three outgoing laser beams, which are combined from six laser sources, and with nine receiving mirrors, the overlap correction is rather complex). In the right-hand panel, we can see that the lidar again reproduces the fine-scale oscillations seen in the radiosonde data, demonstrating the good consistency between the Monge lidar and radiosonde measurements. Comparing the 12 radiosonde launches made during the 2020 campaign to the nightly average lidar temperature, the maximum observed average difference is $3 \mathrm{~K}$ (radiosonde-lidar), with a standard deviation that increases with altitude from $1 \mathrm{~K}$ at $17 \mathrm{~km}$ to $7 \mathrm{~K}$ at $30 \mathrm{~km}$. 

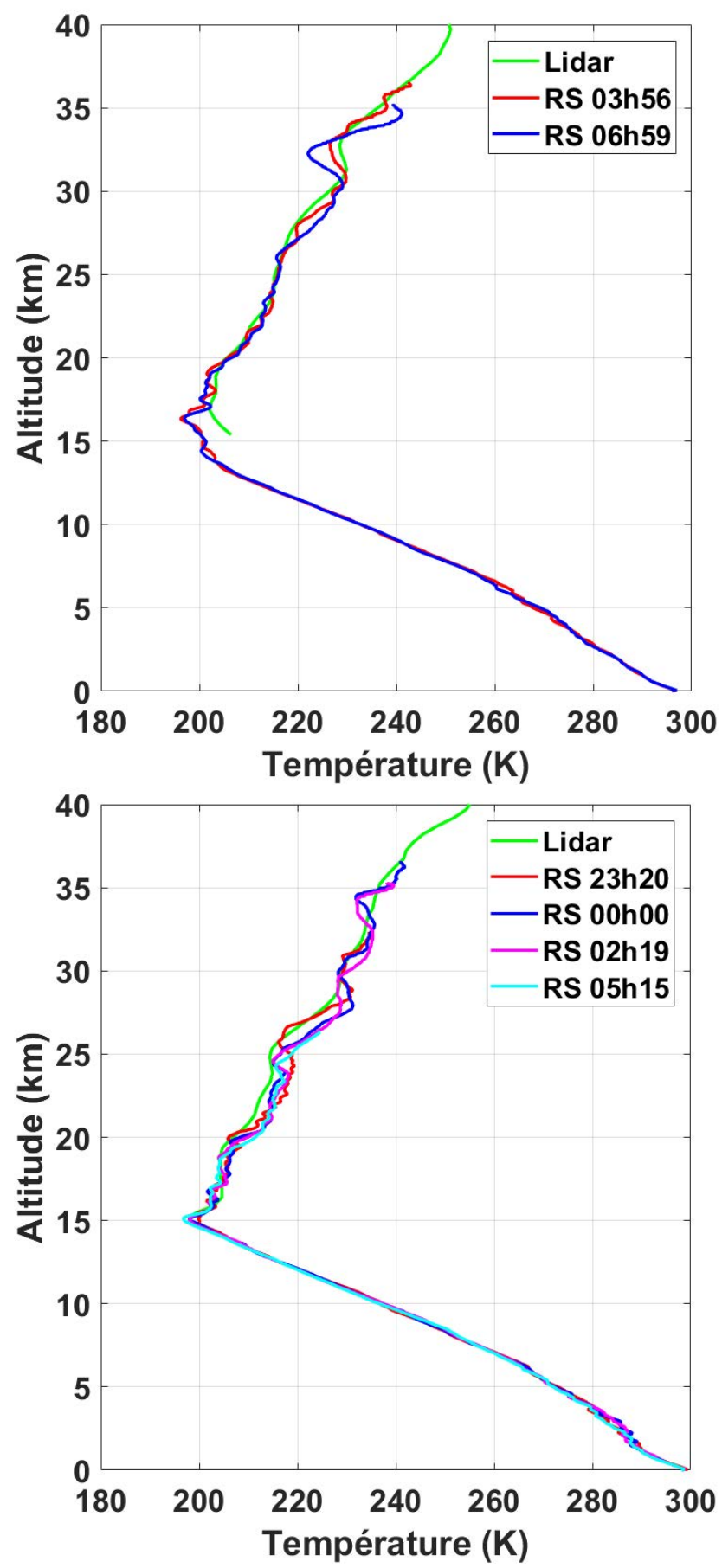

Figure 2. Two examples of temperature profiles from the Monge lidar (green) vibrational Raman channel at $608 \mathrm{~nm}$ and locally launched radiosondes.

\subsection{ICON Satellite}

NASA's Ionospheric Connection Explorer (ICON) satellite was launched on 10 October 2019 into a near-circular orbit at $590 \mathrm{~km}$ with an inclination of $27^{\circ}$. ICON's primary mission is to study the interactions between the neutral atmosphere and ionosphere using instruments that measure winds, temperatures, and composition [46]. For this study, we used the Michelson Interferometer Global High-resolution Thermospheric Imaging (MIGHTI) instrument, which measures both the winds and temperatures in the MLT. MIGHTI winds were found using the Doppler Asymmetric Spatial Heterodyne (DASH) technique on both red and green airglow layers, giving an overall altitude range of 90 to $300 \mathrm{~km}$ [47-49]. MIGHTI temperatures were found using the ratios of the $\mathrm{O}_{2}$ A Band emissions, giving an 
overall altitude range between 90 and $105 \mathrm{~km}$, with a vertical resolution of approximately $2.9 \mathrm{~km}$ [50]. The ICON-MIGHTI data discussed below are within a $1000 \mathrm{~km}$ radius of the launch site for all dates.

Recent validation studies for ICON-MIGHTI thermospheric winds conducted using ground-based Fabry-Pérot Interferometers Makela et al. [51] and specular meteor radars Harding et al. [52] have demonstrated the utility of ICON winds for comparison with ground-based or ship-borne measurements.

\subsection{Sounding of the Atmosphere Using Broadband Emission Radiometry (SABER)}

Temperature measurements from the SABER instrument were used in this study to ensure that the lidar was not producing biased or unrealistic temperature profiles between 15 and $105 \mathrm{~km}$. The vertical resolution for the SABER temperature profiles is given as approx. $2 \mathrm{~km}$, with an estimated uncertainty of 1 to $2 \mathrm{~K}$ between 15 and $60 \mathrm{~km}, 5 \mathrm{~K}$ near

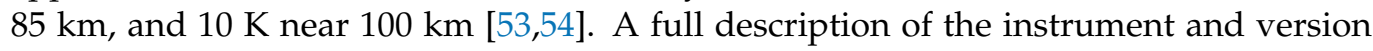
2.0 temperatures is given in Mertens et al. [29].

\subsection{Microwave Limb Sounder (MLS)}

Temperature measurements from the MLS instrument were made using limb measurements of the thermal microwave radiation of the atmosphere. Version 4.0 MLS temperature profiles have a typical vertical resolution of $8 \mathrm{~km}$ at $30 \mathrm{~km}$ altitude, $9 \mathrm{~km}$ at $45 \mathrm{~km}$ altitude, and $14 \mathrm{~km}$ at $80 \mathrm{~km}$ [55]. Further details can be found in Waters et al. [56]. We used MLS in conjunction with SABER to fill in the gaps for cloudy nights during our campaign.

\subsection{Radiosondes}

As part of the Monge 2020 campaign, GRAW radiosondes were launched from the ship throughout the night. The sonde data were used to extend the temperature profiles below $15 \mathrm{~km}$, where the lidar geometric overlap effect is important, down to sea level. We also used the wind speed and direction of the sonde to calculate the zonal and meridional wind speeds below approx. $30 \mathrm{~km}$.

\subsection{ECMWF-ERA5 Reanalysis}

The European Centre for Medium-Range Weather Forecast (ECMWF) ERA5 reanalysis has 137 model levels from the surface to $0.01 \mathrm{hPa}$ (approx. $80 \mathrm{~km}$ ) and a global horizontal resolution of $28 \mathrm{~km}$. ERA5 assimilates satellite measurements of temperature and some winds into calculations of their atmospheric motion vectors [57]. The wind estimates in the free troposphere and lower stratosphere appear to accurately reproduce medium- and longterm wind features at scales down to very large gravity waves [58]. Recent work has shown relatively good agreement between ERA5 temperatures and temperature measurements made using MLS and Rayleigh lidars [59].

\section{Methods}

\subsection{Lidar Temperatures}

Lidars measure the photons that arrive at a receiver telescope when zenith pointing pulsed laser light back-scatters off atmospheric molecules. The raw lidar profiles were quality controlled for obvious outliers, the paralysis of the photon counters at high count rates, cloud cover, and light pollution, following the techniques detailed in [60]. The corrected photon counts were proportional to the vertical profiles of atmospheric density and were normalized using an empirical atmosphere model, MSIS density [61], at $40 \mathrm{~km}$ to obtain the neutral densities at $40 \mathrm{~km}$. Following the method described by Hauchecorne and Chanin [62], the lidar density profile can be used to iteratively calculate a lidar temperature profile with the assumption of a starting pressure at the top of the atmospheric profile. The choice of this "seed pressure" can induce an uncertainty in the top few kilometers of a lidar temperature profile as the iteration converges exponentially towards the true temperature. The seed pressure bias becomes negligible after approximately two scale 
heights ( $\sim 12$ to $15 \mathrm{~km}$ ) [63]. In the case of the temperature profiles calculated for the Monge lidar, the seed pressure altitude was chosen at the point where the signal-to-noise ratio was equal to two in the density profile; we then removed the top $15 \mathrm{~km}$ of the temperature profile (i.e., Monge temperature profiles with a top altitude of $105 \mathrm{~km}$ had a seed pressure taken at $120 \mathrm{~km}$ ). The lidar temperature uncertainty is largely dependent on the Poisson photon counting uncertainty and, thus, the vertical and temporal integration. A typical Monge lidar temperature profile has an uncertainty of less than $0.1 \mathrm{~K}$ in the stratosphere, which increases with altitude. We truncated the temperature profile when the uncertainty exceeded $10 \%$ (i.e., $\pm 20 \mathrm{~K}$ at a $200 \mathrm{~K}$ temperature), which was generally achieved, after 5 min signal integration, near $95 \mathrm{~km}$.

\subsection{Lidar Filtering}

To achieve a lidar temperature uncertainty of less than $10 \%$ at all altitudes in the lidar profile, the raw vertical resolution of the Monge lidar, $75 \mathrm{~m}$, was integrated to $495 \mathrm{~m}$ in order to reduce the Poisson photon counting uncertainty and to comply with the Network for the Detection of Atmospheric Composition Change (NDACC) standards for temperature lidars [64,65]. Our final temperature profiles were filtered using a Savitzky-Golay derivative filter. The "effective vertical resolution" of the final lidar temperature profile after using a differential filter can be found by numerically solving for all the filter coefficients during filter design [66], using a parametric modeling approach to simulate the lidar response [67], or looking up the filter coefficients in a table and plotting them [68]. We chose the last option, and the effective vertical resolution of filtered Monge lidar temperature profiles was $926 \mathrm{~m}$. The lidar temperatures remained gridded at $495 \mathrm{~m}$; however, due to smoothing with a numerical filter, each grid point contained information from adjacent grid points. In this case, the effective vertical resolution was the Full-Width-Half-Maximum (FWHM) of the filter, $926 \mathrm{~m}$.

The longest-period waves we are able to detect were approximately equal to half of our nightly observation period, which ranged from 4 to $9 \mathrm{~h}$. Given that the Brunt-Väisälä frequency (approx. $5 \mathrm{~min}$ ) likely represents an absolute lower bound on wave motion, we chose to integrate the lidar temperature profiles to $5 \mathrm{~min}$. The best practice for lidar studies of GWs is to filter data in time to suppress high-frequency signals that may not be geophysical in origin. However, we wanted to push the analysis as far as was reasonable towards these higher frequencies. We sought to preserve the ability to detect the $30 \mathrm{~min}$ GW ripples reported by Taylor et al. [22], which would have required a resolution on the order of $15 \mathrm{~min}$ (three consecutive five-minute lidar profiles).

\subsection{Wavelet Analysis}

Given that our interest was in detecting high-frequency instabilities and GWs, it was reasonable to assume that the temperature fluctuations could be non-linear, nonstationary, non-Gaussian, and highly variable with time and altitude. To better represent the transients in such a complex signal, we chose to use a Morlet wavelet analysis in place of traditional Fourier methods [69]. Using this technique, we could relate the wave period to the observation time and the vertical wavelength to altitude.

\subsection{Lidar Gravity Wave Estimates}

Temperature perturbations were calculated here with respect to a common temperature profile, which was intended to represent the background temperature state for the night. We chose to use the temperature profile calculated from a nightly average of all the photon count profiles as this background temperature profile. Alternate approaches include using individual background temperature profiles for each perturbation profile that is calculated. These background states can be calculated from smoothed versions of the temperature profiles themselves (e.g., by the moving average, which has problems near the lower and upper altitude ranges of the temperature profile), or from polynomial fits 
to the temperature profiles (e.g., [70], which poorly accounts for perturbations occurring within long-lived MILs).

We attempted to separate the longer-period "background GWs" from potential instabilities by low-pass filtering the lidar temperatures in time. We used a Butterworth filter with a cut-off frequency of $15 \mathrm{~min}$ to find the GWs with periods between $15 \mathrm{~min}$ and $\sim 4 \mathrm{~h}$ [18].

\section{Data}

\subsection{Context of the Campaign}

The Monge lidar is primarily used for military applications during ballistic vehicle launches. We are able to use the lidar data for scientific purposes after a campaign, with the sensitive dates and locations of the measurements removed. The convention that we are adopting to reference dates in our study is to count the days preceding or succeeding the launch date of the rocket $(\mathrm{D}+0)$. Despite not presenting rocket data in this paper, the lidar data we receive are given to us in the context of a rocket campaign. In Figure 3, we present a graphical summary of the five nights of data available to us: MLS (magenta), SABER (blue), ICON (red), 15 min lidar profiles (green), nightly average lidar profiles (dark green), and locally launched radiosondes (orange). The abscissa is a vector of times, in $15 \mathrm{~min}$ increments, with respect to the launch time of the rocket $(\mathrm{D}+0)$. The temperature profiles for each instrument are plotted on this common grid.

This particular lidar campaign took place in the summer of 2020 at tropical latitudes. The lidar was fully operational for three nights (D-3, D+0, and D+1) surrounding the launch of the rocket. There was substantial cloud cover on the nights of D-2 and D-1, which prevented operations. The lidar profile on D-1 represents 20 min of Monge lidar data taken during a gap between the clouds.

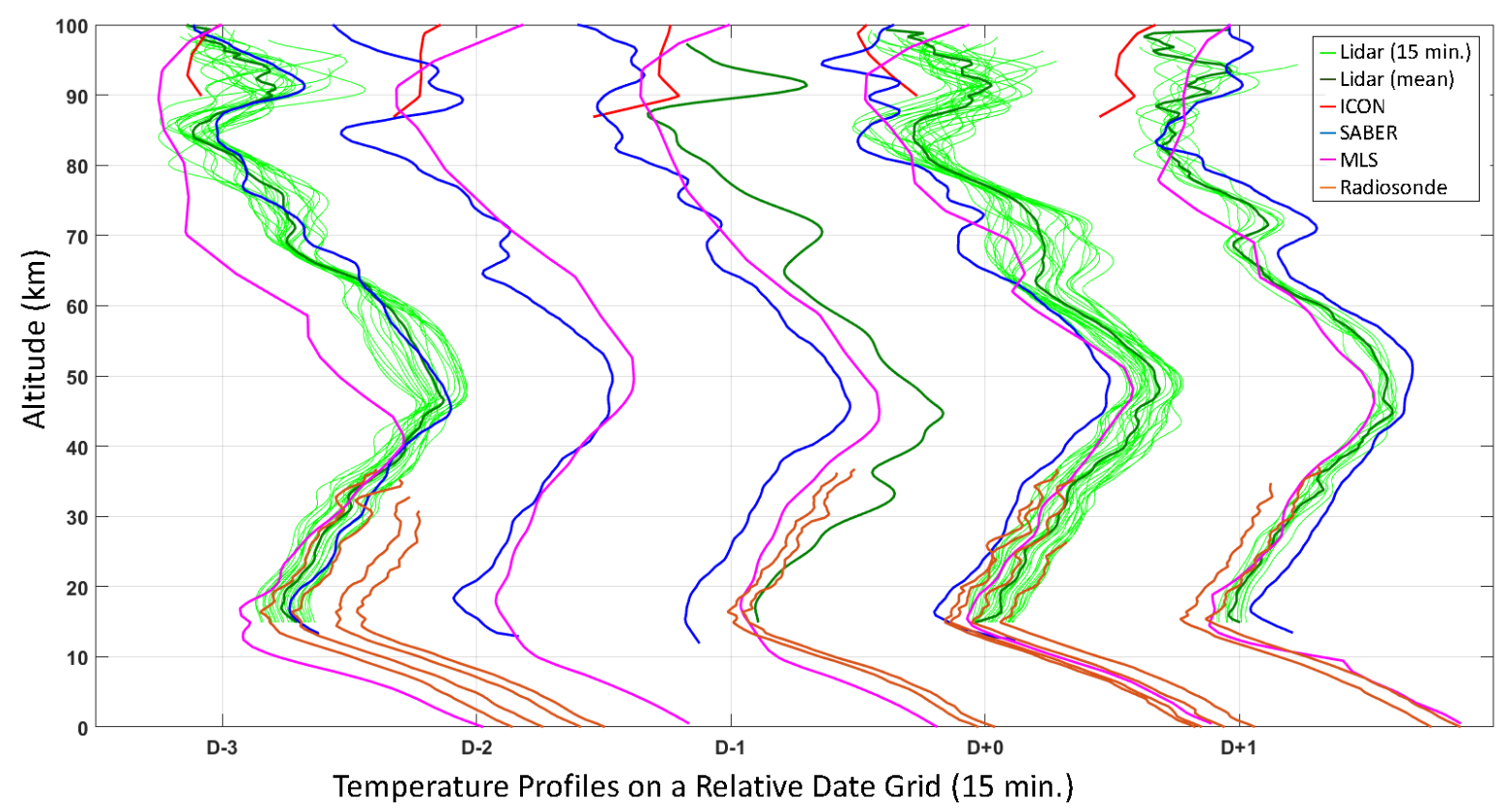

Figure 3. All measurements made during the Monge 2020 campaign. Dates are relative to day zero (D+0) and are re-gridded at 15 min intervals on the ERA5 time grid.

\subsection{Atmospheric Temperature Profiles}

Shown in Figure 4 are four nightly average temperature profiles measured during the 2020 campaign. The nightly averaged lidar temperature profiles were calculated from the nightly average lidar photon count profiles. Likewise, when we present lidar temperature profiles at 15 and $5 \mathrm{~min}$ integrations, these profiles were calculated using the average of lidar photon counts during this period. By comparing Figure 3 to Figure 4, we can make a few observations about each night. On the night of D-3, there was a MIL above $90 \mathrm{~km}$, 
which was clearly seen by both the lidar and SABER and possibly ICON. For the night of D-1, we need to be cautious when making conclusions based on $20 \mathrm{~min}$ of data. However, it appears that the MIL at $90 \mathrm{~km}$ was still present and there was a layer starting to form near $70 \mathrm{~km}$. On this night, ICON was clearly detecting the MIL at $90 \mathrm{~km}$. The following night, $\mathrm{D}+0$, the MIL at $90 \mathrm{~km}$ appears to have started diminishing, while the layer near $70 \mathrm{~km}$ is difficult to interpret. The lower-left panel in Figure 4 appears to show a strange smooth "bump" in the lidar profile around $70 \mathrm{~km}$. If we refer back to Figure 3 for this night, we can see that this bump represents the mean of an extremely variable region of the atmosphere. This variability makes the night of D+0 (fortuitously the night of the rocket launch) the best candidate for finding some interesting dynamics and wave activity. The final night in the series, D+1, shows a sharpening of the MIL at $70 \mathrm{~km}$ and a further diminished MIL at $90 \mathrm{~km}$.
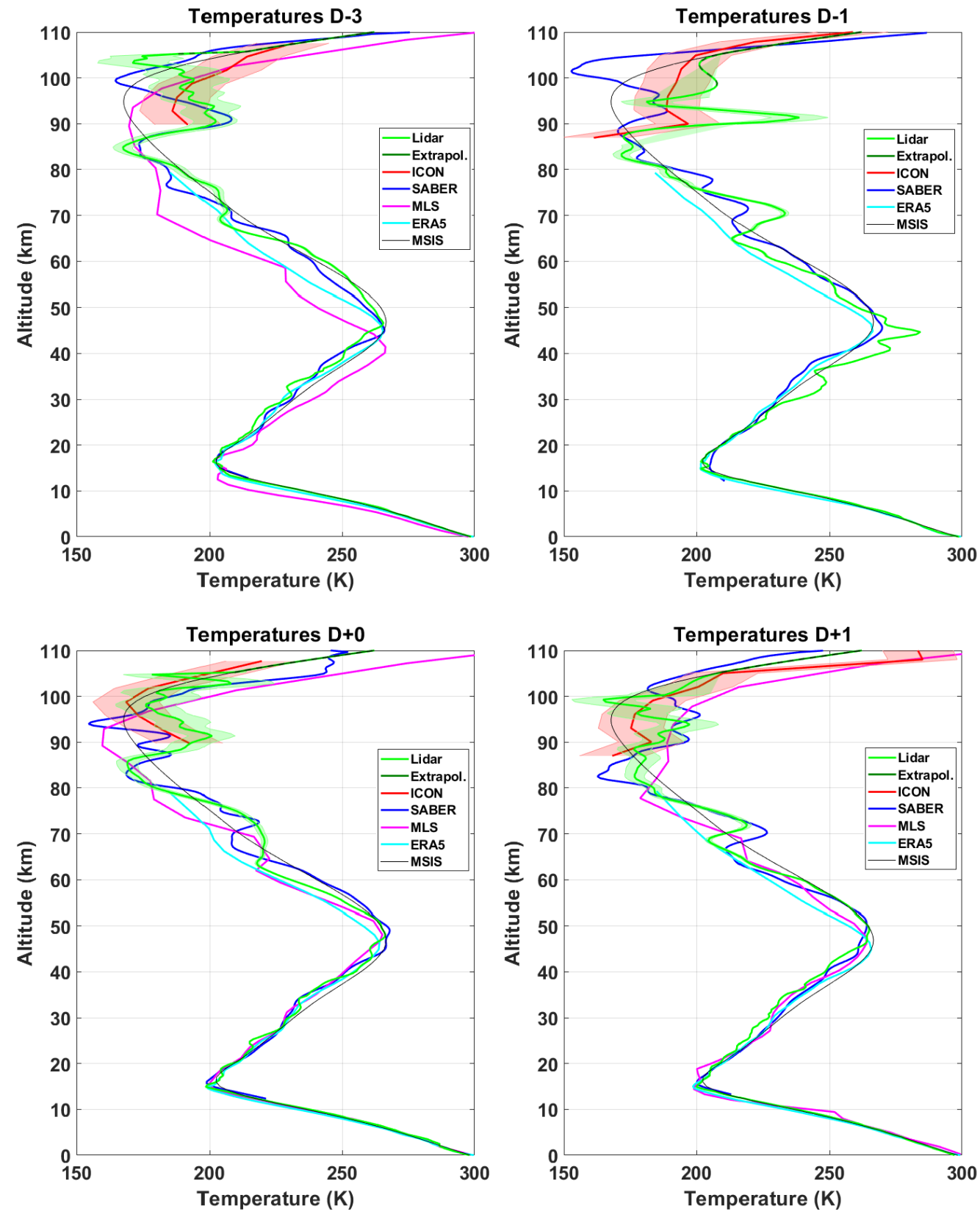

Figure 4. Nightly average temperature profiles made by the Monge lidar (green), extrapolated Monge lidar (dark green), ICON (red), SABER (blue), MLS (magenta), ERA5 (cyan), and MSIS (black). 


\subsection{Lidar Temperature Perturbations}

The three nights (D-1 excluded) of lidar temperature perturbations are presented in Figure 5. The temperature perturbations are presented on the same color scale, over the same vertical range, and with respect to local midnight. The perturbations were taken with respect to the nightly mean temperature and were low-pass filtered at $15 \mathrm{~min}$. Nights D-3 and $\mathrm{D}+1$ were relatively calm. The sloped bands of positive temperature perturbation (teal in Figure 5), which begin at about 70 and $90 \mathrm{~km}$, are evidence of MILs that are descending throughout the night to about 58 and $78 \mathrm{~km}$. Night D+0 is much more dynamic and shows multiple waves of different scales interacting, as well as some high-frequency variations occurring above $85 \mathrm{~km}$. All the variations shown are significant within the $10 \%$ uncertainty of the lidar temperature profiles. We have chosen to be very conservative in reporting our temperature perturbations and to mask all the data (white) that exceeded our error tolerance or were otherwise not suitable for estimating wave activity. Given that D+0 was the most interesting night, had the best-quality data, and was the night that corresponded to the rocket launch, we focused most of the subsequent analysis on this night.
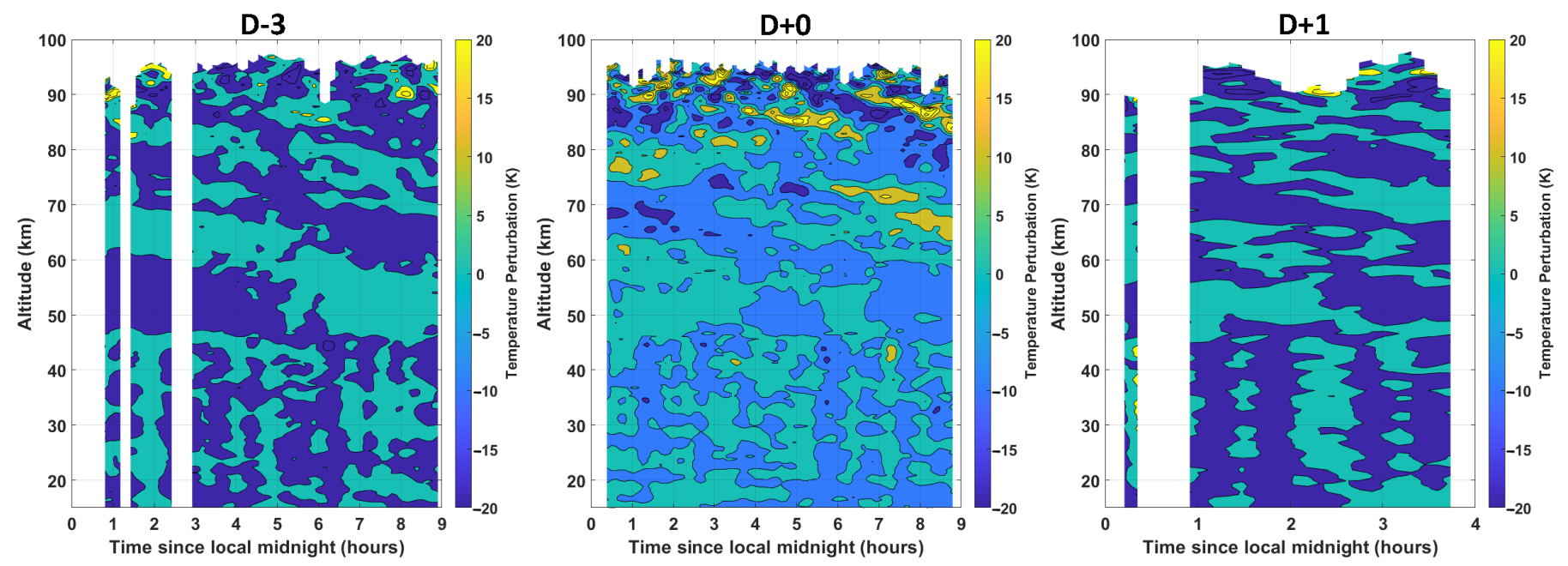

Figure 5. Profiles of $5 \mathrm{~min}$ lidar temperature perturbations with respect to the nightly average lidar temperature profile. Perturbations were low-pass filtered with a cut-off frequency of $15 \mathrm{~min}$. The three nights with measurements longer than $4 \mathrm{~h}$ are shown.

\subsection{Validation of ICON Temperatures}

The 2020 Monge campaign provided a unique opportunity to validate the newly launched ICON satellite temperature using a high-powered Rayleigh lidar. In Figure 6, we have re-plotted Figure 4 from 85 to $110 \mathrm{~km}$ in an effort to assess the ICON temperatures in the MLT. On night D-3, the ICON temperatures were not statistically different from the Monge lidar temperatures between 90 and $103 \mathrm{~km}$ and were equal to the SABER temperatures between 94 and $97 \mathrm{~km}$. It is likely that the temperature differences outside these altitude ranges can be attributed to the comparatively coarse vertical resolution of ICON, the temporal and spatial coincidence between the three instruments (approx. $\pm 700 \mathrm{~km}$ and $\pm 8 \mathrm{~h}$ ), and tidal effects. Tidal effects at tropical latitudes can account for up to a $15 \mathrm{~K}$ temperature difference at $115 \mathrm{~km}$, depending on the phase offset between ICON and the lidar Hagan and Forbes [71]. On D-1, it appears that all three instruments saw a layer above $90 \mathrm{~km}$. D+0 and D+1 were the best comparisons between the lidar and ICON. The measurements were equal over the entire overlap altitude, and they followed the same general temperature profile. Excluding night D-1 (only 20 min of lidar data), the maximum average temperature difference (ICON-lidar) was $-16 \mathrm{~K}$ at $95 \mathrm{~km}, 1 \mathrm{~K}$ at $100 \mathrm{~km}$, and $24 \mathrm{~K}$ at $105 \mathrm{~km}$. The standard deviation was approx. $4 \mathrm{~K}$ below $100 \mathrm{~km}$. 

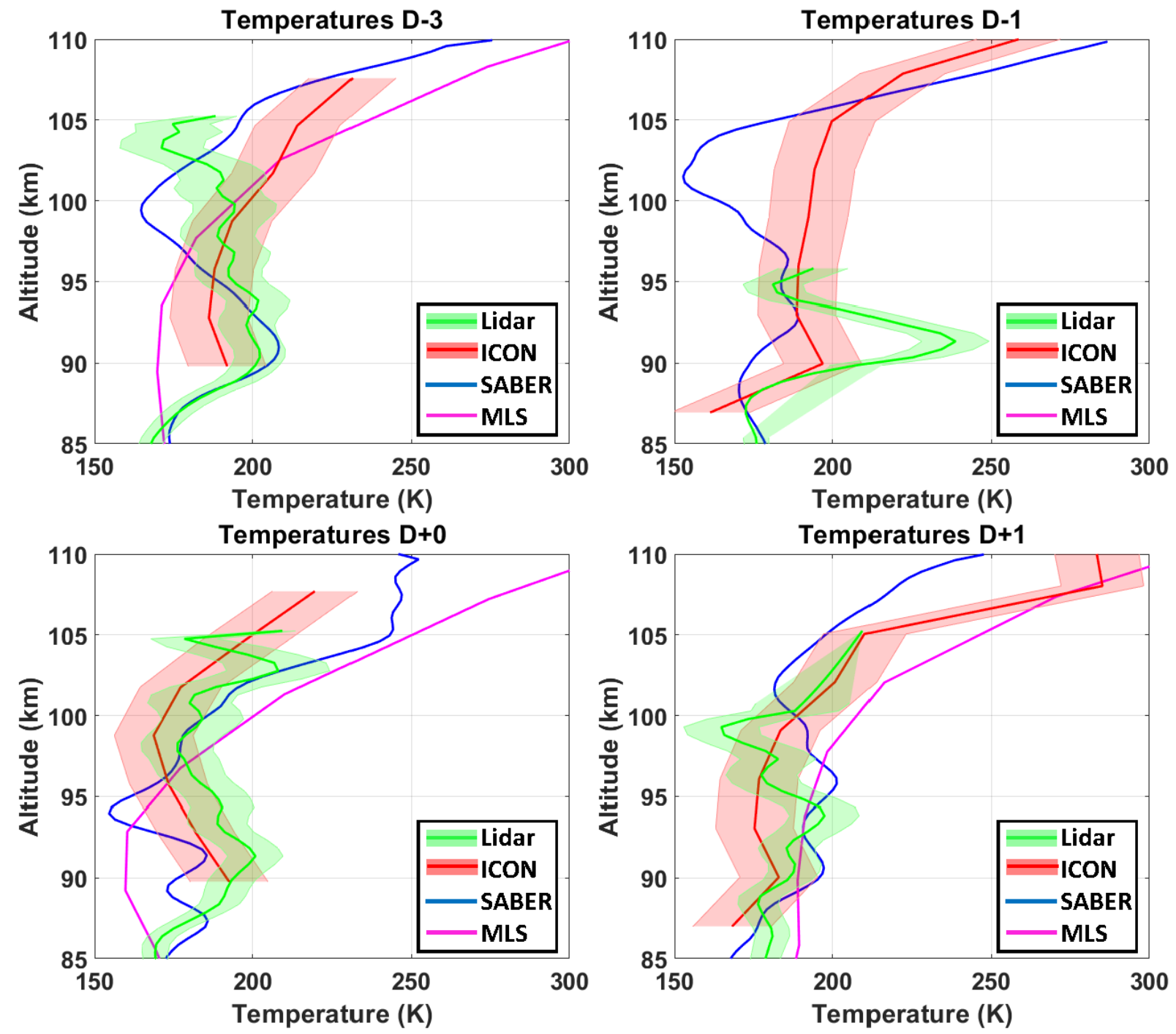

Figure 6. Nightly average temperature profiles created by Monge lidar (green), ICON (red), SABER (blue), and MLS (magenta) covering only the MLT.

\subsection{Merged Temperatures and Winds}

In Figure 7, we have used the data from the Monge lidar, local radiosondes, ERA5, and ICON to attempt to reconstruct approximate nightly average profiles of the temperature, local Brunt-Väisälä frequency, and zonal and meridional winds. For temperature, we took the radiosonde profile closest to the middle of the lidar measurement from the sea surface to $15 \mathrm{~km}$. We then merged the Monge lidar Raman, low-gain Rayleigh, and high-gain Rayleigh to extend the temperatures from 15 to $110 \mathrm{~km}$.

The static stability is shown to indicate the transition between the troposphere and stratosphere, the presence of strong MILs, possible regions where instabilities may be found $\left(N^{2}<0\right)$, and the transition from the mesosphere to the thermosphere.

The zonal and meridional components of the winds were taken from the radiosondes from the sea surface to the balloon burst altitude, ERA5 winds were then taken up to $80 \mathrm{~km}$, ICON winds were generally available above $90 \mathrm{~km}$, and the region between ERA5 and ICON was interpolated using a cubic spline. On the night of D-3, Figure 7 (upper left), we can see that the static stability increased gradually above $15 \mathrm{~km}$, indicating a smooth transition through the tropopause. There were elevations in $N^{2}$ near $70 \mathrm{~km}$ and below $90 \mathrm{~km}$, which corresponds to the bottom side of the MILs. There is a small region of negative $N^{2}$ at $104 \mathrm{~km}$, which may support instabilities. The westward zonal winds were small in the lower troposphere and increased rapidly in the upper troposphere between 
5 and $15 \mathrm{~km}$. Around the tropopause, in the lower stratosphere, the winds reversed direction and, above $18 \mathrm{~km}$, began to blow eastward. A small local maximum was located near $55 \mathrm{~km}$, at the top of the stratopause. The maximum in the eastward wind speed was reached near $70 \mathrm{~km}$, which corresponds to the altitude where the lower MIL was beginning to form. Above this altitude, the eastward zonal wind slowed and reversed. The next maximum wind speed was a westward flow near $90 \mathrm{~km}$, which corresponds to the altitude of the upper MIL. Above $90 \mathrm{~km}$, the wind direction reversed again and reached a maximum westward flow near $105 \mathrm{~km}$. Above $105 \mathrm{~km}$, the thermospheric wind returned to eastward flow. The meridional wind was southward in the troposphere and slowed to near zero through much of the stratosphere. Like the zonal wind, the meridional wind had local maxima located near 55, 70, and $90 \mathrm{~km}$, which corresponded, respectively, to the top of the stratopause, the lower MIL, and the upper MIL. The meridional component of the thermospheric wind was northward. It is interesting to note that each wind reversal appears to be associated with an increase in the local Brunt-Väisälä frequency associated with an inversion layer (tropopause, stratopause, lower MIL and upper MIL).
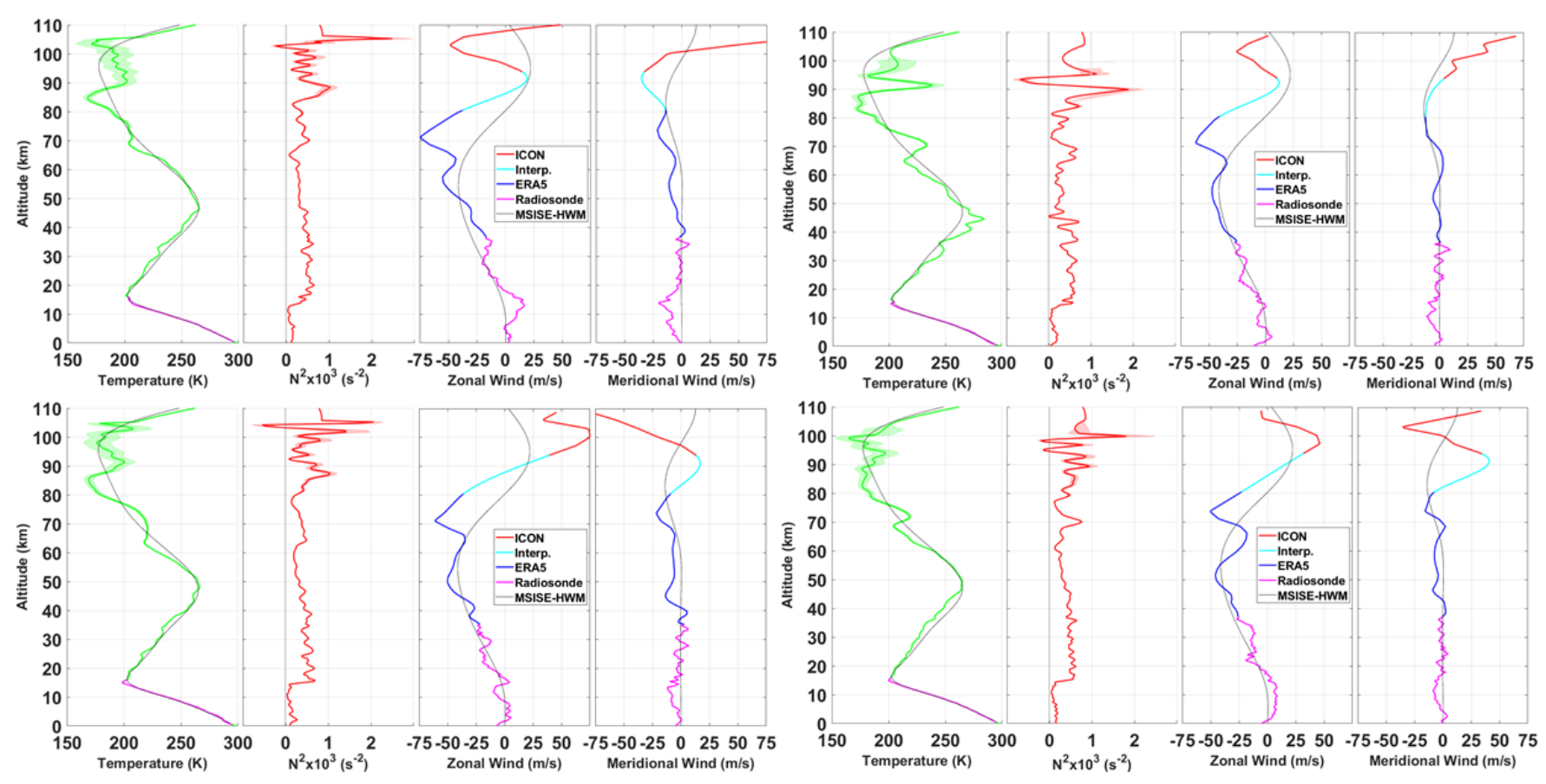

Figure 7. Profiles of merged temperature (green), Brunt-Väisälä frequency (orange), estimated composite zonal wind, and estimated composite meridional wind (magenta, blue, cyan, and red) for D-3 (upper left), D-1 (upper right), D+0 (lower left), and D+1 (lower right).

On the night of D-1, Figure 7 (upper right), the zonal and meridional winds closely followed the MSISE-HWM wind climatologies. There were zonal wind reversals associated with the MILs at both 70 and $90 \mathrm{~km}$. We should not overinterpret the static stability profile, as it is based on $20 \mathrm{~min}$ of lidar data.

On the night of D+0, Figure 7 (lower left), we see a much sharper jump in the static stability in the tropopause region, which was associated with an eastward jet at $15 \mathrm{~km}$. There appears to have been clear wave activity in both the temperature and wind profiles throughout the stratosphere between 15 and $45 \mathrm{~km}$. Recall from Figure 3 that the smooth shape of the "lower MIL" is actually the average of several fast waves superimposed. The mid-point of this wave activity near $70 \mathrm{~km}$ was associated with the maximum westward wind speed. Near $90 \mathrm{~km}$, the approximate altitude of the upper MIL, the zonal wind was close to zero, and we see a maximum in the northward flow of the meridional wind. 
Above $95 \mathrm{~km}$, the zonal wind was strongly eastward with a local minimum near $107 \mathrm{~km}$. The meridional wind was completely reversed and was flowing south.

On the night of D+1, Figure 7 (lower right), we again see a sharp increase in the static stability at the tropopause; however, it was not accompanied by similar features in the wind profiles. Local maxima can be seen in the zonal wind profile at 50 and $74 \mathrm{~km}$, which can be associated with the stratopause and lower MIL, respectively. At these altitudes, weak features can also be seen in the meridional wind profile. At $95 \mathrm{~km}$, near the altitude of the upper MIL, we see a wind reversal happening in both the zonal (near $97 \mathrm{~km}$ ) and meridional (near $92 \mathrm{~km}$ ) winds. A final meridional wind reversal is seen at $105 \mathrm{~km}$. The lidar only measured for $4 \mathrm{~h}$ on this night, so the temperature profile begins to strongly follow the a priori one above $100 \mathrm{~km}$.

When we plot the vertical gradients of the profiles as in Figure 7, we can investigate the behavior of the temperature and winds as an indicator of forming MILs. In Figure 8, we show the temperature gradient as a function of altitude for temperature using red bars. The slope of the bars represents the vertical rate of change in the temperature gradient, $\frac{d}{d z} d T$. By representing the data in this way, we wish to show the bottom-side lapse rates of MILs (and forming MILs) more clearly. In general, we can see that the lapse rate is negative in the troposphere and mesosphere and positive in the stratosphere and thermosphere. There is evidence of wave-driven changes in the lapse rate in both the stratosphere and mesosphere. We have highlighted the regions in the mesosphere where the rate of change in the temperature gradient is positive and associated with the bottom side of the MILs observed near 70 and $90 \mathrm{~km}$. The zonal and meridional wind lines represent the vertical gradient of the wind in the north and east directions.

In the first panel, night D-3, we see that a lower MIL began to form near $65 \mathrm{~km}$ where the "rate of change of cooling-positive lapse rate gradient" goes towards zero. In Figure 4 (upper left), we can see that there was no pronounced MIL present, so we interpret this positive lapse rate gradient as a MIL in the process of developing. In this lower purple region, we also see that both the zonal and meridional winds changed and reversed direction. In the upper purple region, associated with the bottom side of the upper MIL at $90 \mathrm{~km}$, we see that the zonal wind returned to eastward flow and the meridional wind experienced a second reversal and was again flowing south. We can also see that the change in the zonal wind very closely followed the lapse rate gradient above $85 \mathrm{~km}$, experiencing a reversal near $98 \mathrm{~km}$.

In the second panel, night D-1, we can see that the lower MIL had descended in altitude (the bottom side then extended from 59 to $67 \mathrm{~km}$ ) and had a clear positive lapse rate. In Figure 4 (upper right), we can see that the lower MIL was more developed. Similarly to in the first panel, we see that the change in the zonal and meridional winds again experienced a reversal, with the maximum westward wind at the maximum of the MIL and the maximum southward wind occurring a few kilometers higher. In the upper MIL, we see that the winds had recovered and were again flowing northwest. There was a zonal wind reversal from 95 to $102 \mathrm{~km}$. There is a small feature in the gradient of the lapse rate, which corresponds to a reduction in the meridional wind gradient at $98 \mathrm{~km}$.

In the third panel, night D+0, we see the same pattern of wind reversal associated with the bottom side of the lower MIL. Recall from the comparison of Figure 3 and Figure 4 (lower left) that we saw that the lower MIL was a result of many quickly varying waves superimposed that created a smooth mean temperature profile. In the region above the upper MIL at $89 \mathrm{~km}$, we have a wind reversal in both the zonal and meridional winds. On this night, the increase in the meridional wind gradient followed the gradient of the temperature lapse rate closely between 89 and $105 \mathrm{~km}$.

In the fourth panel, night $\mathrm{D}+1$, we see the same pattern of wind reversal in both the meridional and zonal winds associated with the bottom side of the lower MIL. The same pattern also holds true in the region above the upper MIL, where both wind components experienced a reversal. There is some vertical offset between the temperature lapse rate gradient and the meridional wind gradient. We add a note of caution with respect to the 
interpretation of the zonal winds between 75 and $95 \mathrm{~km}$. The ICON zonal wind profile did not extend as far down into the atmosphere on this night, so the spline interpolation between ERA5 and ICON is less constrained.
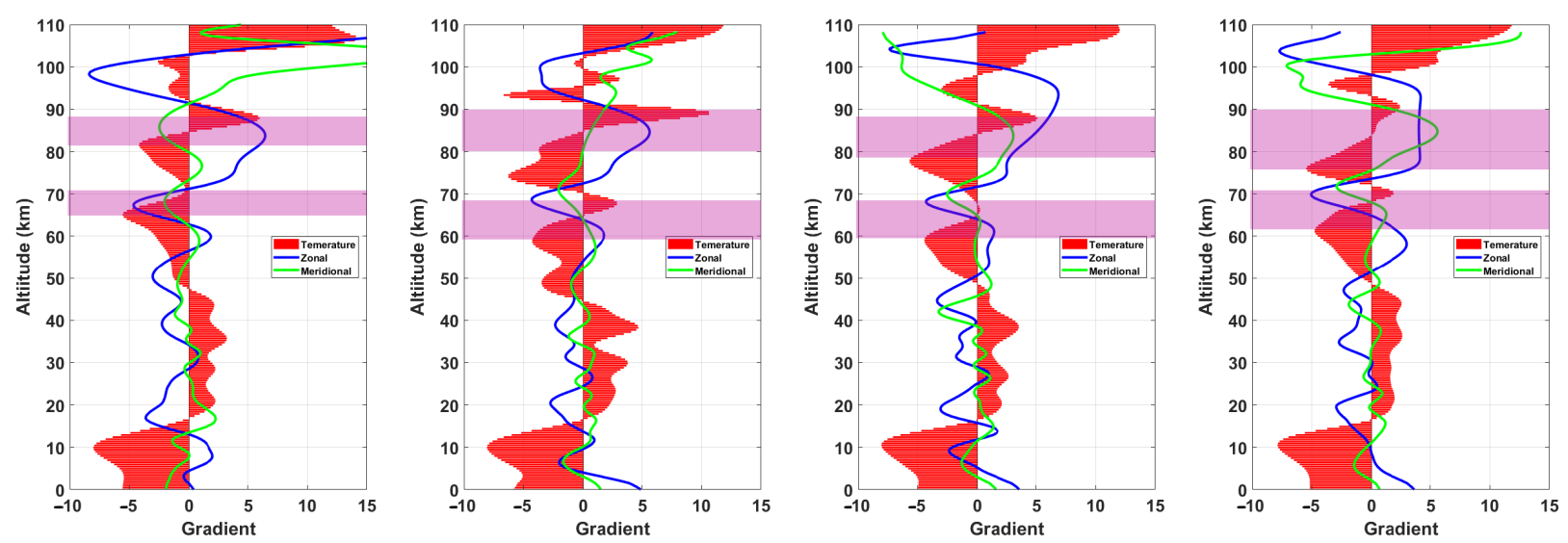

Figure 8. Profiles of gradients of temperature (red), zonal wind (blue), and meridional wind (green). Purple highlighted region represent regions in the mesosphere where the temperature gradient was becoming more positive. From left to right, the panels present the nights of D-3, D-1, D+0, and D+1.

\section{Results}

\section{Case Study Night of $D+0$}

We chose to make a case study of the night of the rocket launch because it had the most interesting features from both a geophysical and from a military engineering perspective. In Figure 9, we have reproduced the middle panel of Figure 5 and superimposed a white dashed grid on which we conducted a wavelet analysis. We centered the grid at $5 \mathrm{~km}$ intervals from 50 to $90 \mathrm{~km}$ and at every hour on the half hour. The top of the figure is masked when the temperature uncertainty in the 5 min lidar profile exceeded $10 \%$. We did not extend the analysis to $95 \mathrm{~km}$, as some data are under the mask. Our intent here was to perform a very conservative perturbation analysis so that we could maintain a high degree of confidence in the detection of small-scale features.

In Figure 10, we see nine frames that represent the continuous wavelet transform scalogram taken along the horizontal grid lines shown in Figure 9. On the ordinate of each scalogram subplot is the period of the wave (the scale is $\log (2)$ ), and the abscissa corresponds to the number of minutes since the start of the lidar measurement at 00:23 local time. The grayed-out region of each scalogram is the Cone of Influence (CoI), which represents the period-time spaces that are influenced by the edges of the dataset (e.g., near the top of each sub-figure, more space is grayed out, as fewer wavelets of periods greater than $120 \mathrm{~min}$ can be fitted into a $9 \mathrm{~h}$ dataset). The color scale of the plots represents the amplitudes of the temperature perturbations of each wave. N.B. the scale of the perturbations increased with altitude. The temperature perturbations at $90 \mathrm{~km}$ can be an order of magnitude larger than the temperature perturbations at $50 \mathrm{~km}$. 


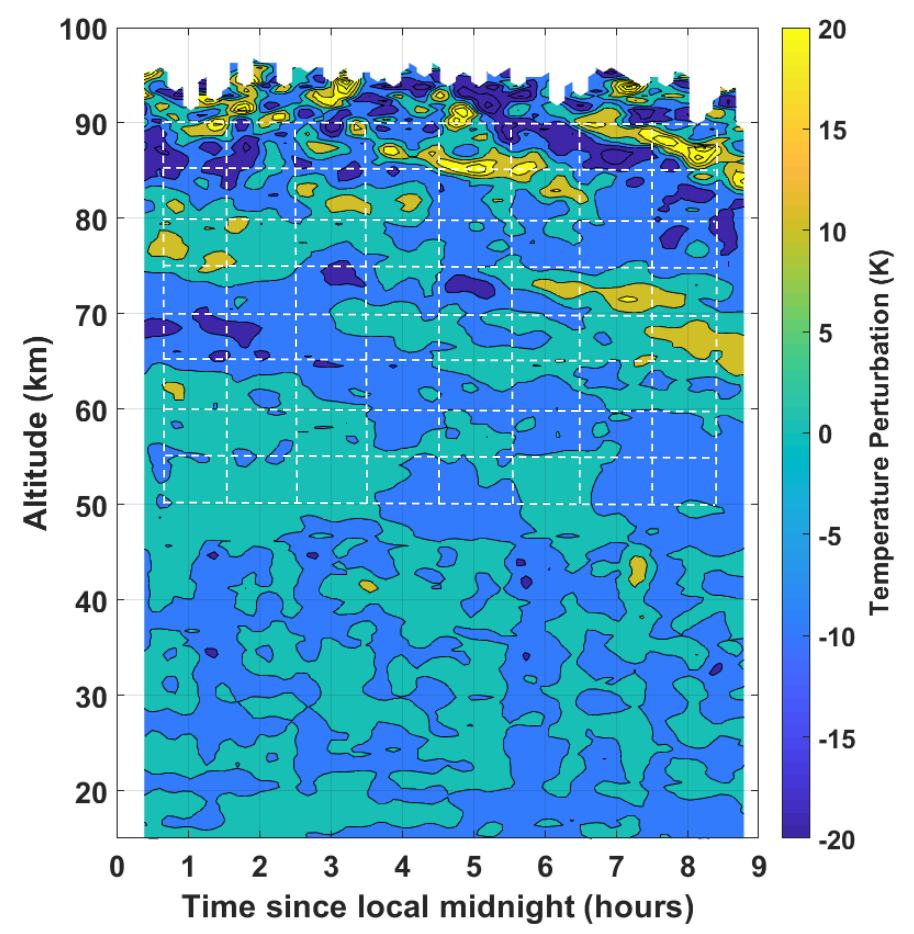

Figure 9. Monge lidar temperature perturbations and analysis grid for the night of $\mathrm{D}+0$.

In general, the scalogram panels for altitudes below $80 \mathrm{~km}$ appear to contain only one or two waves with periods between 30 and $120 \mathrm{~min}$, which contain most of the energy. In particular, a wave with a period between 50 and 55 min appears at multiple altitudes. Another wave with a period between 90 and 112 min appears at 50, 55, 70, and $75 \mathrm{~km}$. Higher-frequency waves appear irregularly and contain substantially more energy than the longer-period waves. Two good examples occur in the panel at $50 \mathrm{~km}$, where large temperature perturbations exist after 120 and $360 \mathrm{~min}$. These two events had periods of 15 to $22 \mathrm{~min}$ and durations of less than $30 \mathrm{~min}$. The same pattern exists at $75 \mathrm{~km}$, where two more high-frequency events exist within the CoI. In particular, the event near $330 \mathrm{~min}$ with a period of 17 to $21 \mathrm{~min}$ was well removed from the CoI and the minimum period of the wavelet transform $(\sim 14 \mathrm{~min})$. This event has relatively well-defined edges in frequency-time space, indicating a wave packet with a rather tight distribution of periods over a short interval of time.

At $80 \mathrm{~km}$, the scalogram shows a marked increase in wave energy at both low and high frequencies. There is a wave mode spanning $\sim 55$ to $75 \mathrm{~min}$, two hot spots corresponding to a period of $\sim 45 \mathrm{~min}$, and multiple periods at higher frequencies throughout the night. The panel representing $85 \mathrm{~km}$ has one dominant high-frequency event that saturates the scalogram occurring at approximately $430 \mathrm{~min}$. Checking Figure 9, observing the intersection of the $85 \mathrm{~km}$ grid line and the $8.5 \mathrm{~h}$ grid line, we can see a local minimum in the temperature perturbation map surrounded by local maxima. The isolines on the temperature perturbation map are very close together, indicating that the local temperature gradient could support an instability. We investigated the significance of this possible instability in the raw lidar data, and it appears to be real and not an artifact in the data. At $90 \mathrm{~km}$, the extreme feature disappeared, and the wave periods returned to the pattern seen below $80 \mathrm{~km}$. The transient nature of this phenomenon lends further credence to the idea that this could be an instability of the type reported in $\mathrm{OH}$ camera data by Sedlak et al. [23]. 

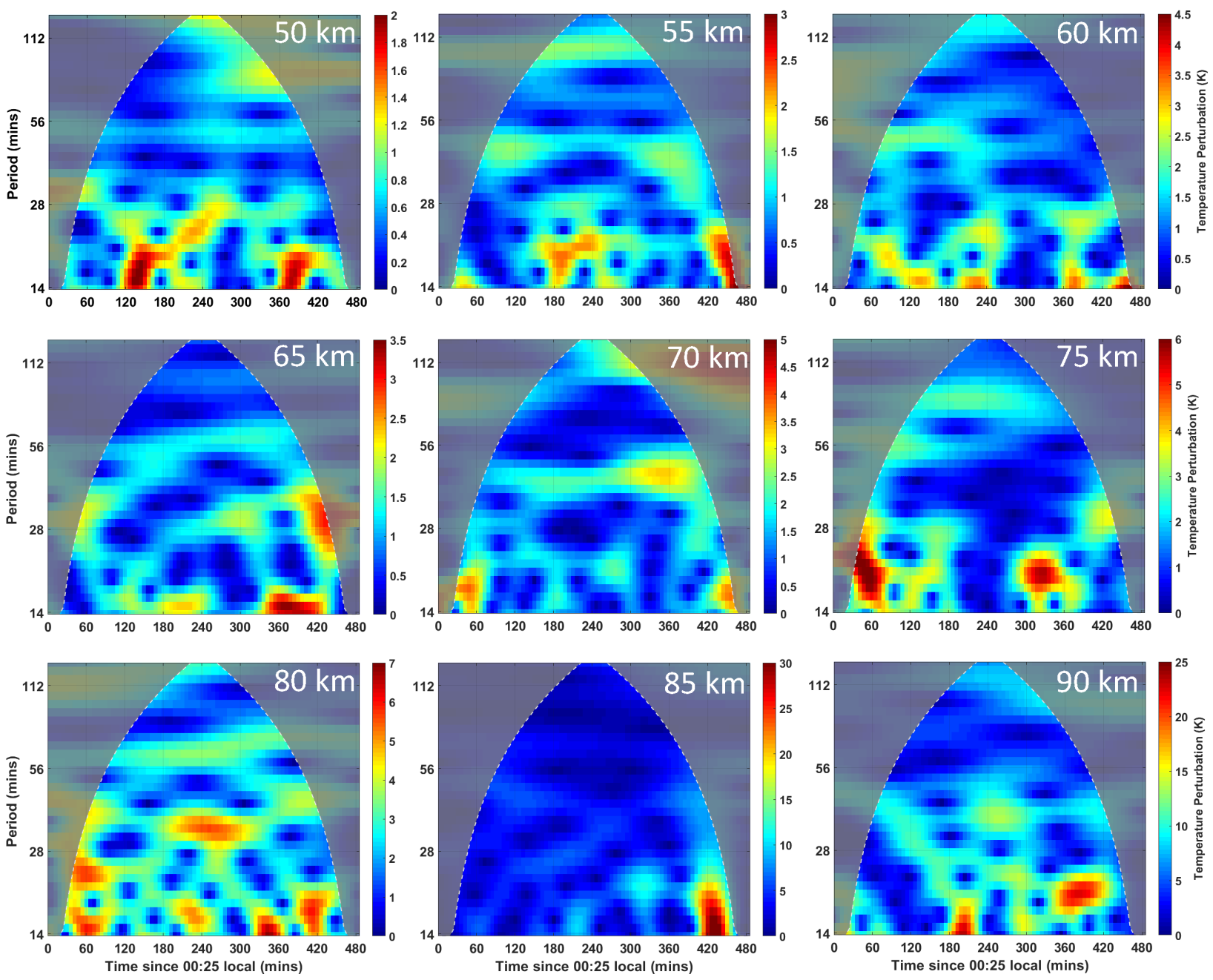

Figure 10. Continuous Morlet wavelet transform of the lidar temperature perturbations on the night of D+0. Scalograms are given at nine altitudes for wave period as a function of measurement time.

In Figure 11, we see nine frames that represent the continuous wavelet transform scalogram taken along the vertical grid lines shown in Figure 9. On the ordinate of each scalogram subplot is the vertical wavelength in kilometers (the scale is $\log (2)$ ), and the abscissa corresponds to the altitude of the lidar measurement. We can make a few observations: first, at high altitudes, there appear to have been only one or two waves, which contained the majority of the energy in the scalogram; second, at 7:30 and 8:30, we see large temperature perturbations with vertical wavelengths of 7 and $4 \mathrm{~km}$, respectively. These features correspond to the bottom side of the same wave feature from Figure 9, which we identified at $85 \mathrm{~km}$. 

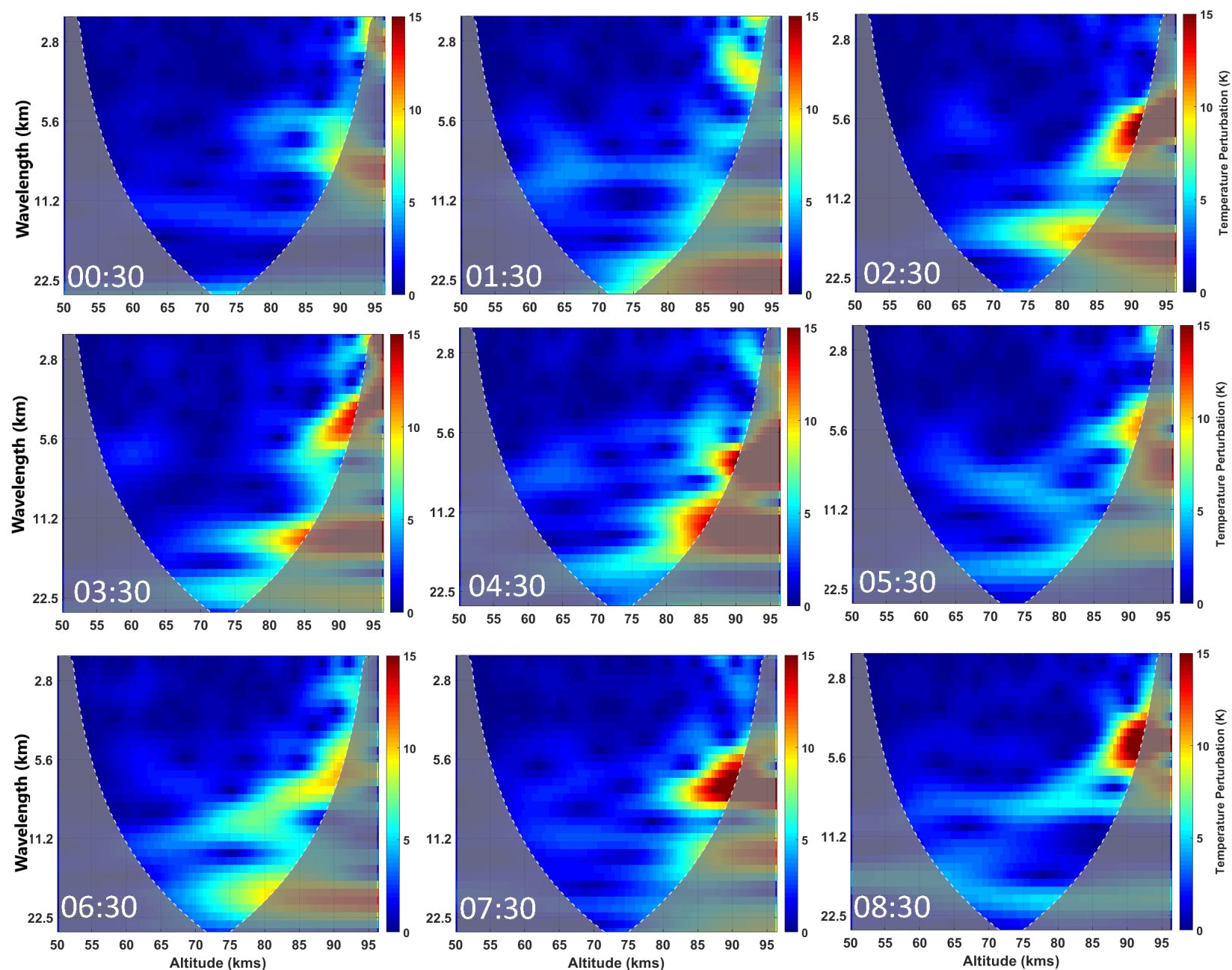

Figure 11. Continuous Morlet wavelet transform of the lidar temperature perturbations on the night of D+0. Scalograms are given at hourly intervals and represent vertical wavelength as a function of altitude.

\section{Discussion}

We have presented a series of a few high-resolution lidar profiles taken by one of the world's most powerful Rayleigh lidars aboard the ship Monge and used supporting information from the new ICON satellite to help in our analysis of a case study. The limited nature of the available datasets us to make several assumptions regarding the nature of the GWs and winds under consideration. We recognize that we were not able to fully evaluate all the GW parameters (intrinsic wave speed, wave propagation direction, realistic energy dissipation rates, etc.); however, some reasonable discussion of the high-resolution vertical results can still take place.

Starting with the night of D+0 in Figure 3, we see rapid variations in the $15 \mathrm{~min}$ integrated temperature profiles between 60 and $75 \mathrm{~km}$ associated with the lower MIL. This is consistent with the theory presented by Hauchecorne et al. [11] that these variations are likely shorter-period GWs breaking through interactions with the mean wind rather than longer-period planetary waves. Figure 8 (all panels) seem to support this conclusion, as we see wind reversals associated with the bottom side of the lower MIL. Our interpretation is that eastward-traveling GWs encounter a zero-wind line at these altitudes, effecting a change in the wind and temperature change. Unfortunately, the wind information between 30 and $80 \mathrm{~km}$ coming from ERA5 does not contain the high-resolution variations in wind speed that would best compare with our lidar data. However, it is encouraging that we see the maxima and minima of the derivative of the wind gradients at approximately the same altitudes where we see our temperature gradient features. 
Furthermore, concerning the lower MIL, we see drastically different pictures of this layer in Figures 3 and 4. On D-2, D-1, D+0, and D+1, SABER measured an inversion layer near $70 \mathrm{~km}$ that we can refer to as a lower MIL. These are "snapshot" measurements and generally correspond to the nightly average lidar profile. The exception is the night of $\mathrm{D}+0$, where the nightly average lidar profile was averaging over a highly variable region of the atmosphere and shows a "smooth bump" rather than the sharper layer seen by SABER. This observational mismatch raises concerns over MIL identification, MIL variability, and optimal data integration when comparing MIL datasets created by satellite and ground-based observatories. We can also raise questions as to what constitutes a MIL: How long must it persist? Over what horizontal and vertical range must it extend? What is a sufficient bottom-side temperature gradient? What is the range of phase speeds that separates a MIL from faster waves? How much variation in MIL amplitude due to the superposition of shorter-period waves is acceptable? Is the wind gradient a better metric than the temperature gradient for defining a lower MIL?

Above $85 \mathrm{~km}$, the wind measurements from the ICON satellite reproduce many of the medium-scale structures we see in the temperature data. Particularly interesting is the comparison of the zonal wind reversal above $87 \mathrm{~km}$ in Figure 9 (first panel), where the zonal wind gradient follows the temperature lapse rate gradient almost exactly. In the second panel, the small reduction in the meridional wind gradient measured by ICON at $97 \mathrm{~km}$ is also seen as a change in the temperature gradient as measured by the lidar. The reproduction of small-scale features in the temperature and the winds by two independent instruments gives us confidence that we are detecting real geophysical variations as opposed to statistical variability in the measurements. In panels three and four, we see that the meridional wind was changing in the same sense as the temperature gradient lapse rate and resulted in a wind reversal and net southward flows. The wind behavior seems to also support the theory presented by Hauchecorne et al. [11], Meriwether and Gardner [26] that the upper MIL is formed by higher-frequency gravity waves breaking at higher altitudes. If we refer back to Equation (1), we can assume that longer-period waves, such as planetary waves, will be more strongly affected by the Coriolis parameter and will be more likely to travel zonally. However, faster GWs may still retain some substantial meridional wave component, which could interact with the mean meridional wind component. We offer the interpretation that, on D-3 and D-1, the bulk of the higher-frequency waves were traveling west to east and upon breaking, and had a strong-enough impact to reverse the zonal wind between approx. 90 and $105 \mathrm{~km}$. Above this height, the thermospheric zonal wind was undisturbed. On either the night of D-1 or D+0, the bulk gravity wave field may have turned northward, as we see that the meridional components of the winds were reversed on the nights of D+0 and $D+1$. We can speculate that, perhaps, the change in the direction of GW propagation provided much of the energy we see on the night of $\mathrm{D}+0$.

The scalogram analysis as a function of altitude, Figure 10, provides us with an interesting view of the GW field over the course of the night. We saw that, at altitudes below $80 \mathrm{~km}$, there were only two or three medium-frequency waves, which contained most of the energy. This result supports the conclusion made by Sica and Russell [72] that, at any given time, there are only a discrete number of dominant non-breaking waves in the middle atmosphere. The universal spectrum of GWs [3] may be the result of low-resolution spectral analysis techniques or long-term averaging, rather than an accurate description of the atmosphere at any given time. The scalogram analysis as a function of altitude also shows two or three high-frequency events, which contain much more energy than the background wave field. These events have periods on the order of 15 to $20 \mathrm{~min}$ or less, and vertical scales of 4 to $7 \mathrm{~km}$, and last for a very brief period of time. We also see an increase in the occurrence and intensity of these events between 80 and $90 \mathrm{~km}$-most notably in the statically unstable bottom side of MILs. The observations reported by $\mathrm{OH}$ airglow imagers, at $87 \mathrm{~km}$, which show small-scale GW instabilities and turbulence [23], on the same temporal scales, suggest that the high-frequency "hot spots" in our scalograms may be the same phenomena. The scalogram analysis as a function of vertical wavelength 
shows that, for vertical wavelengths between 2 and $22 \mathrm{~km}$, most energy was present above $80 \mathrm{~km}$, which is consistent with the theoretical work for wind-wave interactions given by McLandress and Ward [36].

\section{Conclusions and Summary}

In this article, we have (1) shown the technical upgrades that have been made to the Monge lidar, allowing very-high-resolution studies of the atmospheric dynamics between the sea surface and the MLT to be conducted; (2) conducted the first comparison of ICON temperatures to Rayleigh lidar temperatures and found good agreement; (3) combined radiosonde, lidar, ERA5, and ICON to create vertical profiles of the temperature and winds from the sea surface to the thermosphere; (4) made a connection between the gradient of the temperature lapse rate and the increase in the gradient wind fields; and (5) reported measurements of small, short-lived, high-energy events shown in a scalogram analysis of lidar temperature perturbations.

We conclude that we have observed GW waves breaking on the mean winds near $70 \mathrm{~km}$, associated with the evolution of a MIL over the course of a night of lidar observations. This conclusion is consistent with the 2D gravity wave-breaking model presented by Hauchecorne et al. [11], which proposed a wave-saturation mechanism for GW breaking within MILs. These wind-wave interactions show that the gradient of the lapse rate on the bottom side of MILs is a useful metric to compare against wind-gradient change. We also conclude that the small-scale, transient temperature perturbations measured by the lidar are the vertical analog to measurements of GW instabilities conducted in the horizontal plane by $\mathrm{OH}$ airglow imagers near $87 \mathrm{~km}$.

Further high-resolution measurements of small-scale MLT dynamics, which are important for ballistic flight studies, would greatly benefit from further enhancing the Monge lidar for daytime operations and the addition of a co-located Doppler wind lidar. With highresolution profiles of both wind and temperature, we would be able to measure the GW propagation direction and energy dissipation rates, and assess the impact on long-period waves such as tides.

Author Contributions: Conceptualization, R.W., M.M., A.H., C.T. and Y.C.; methodology, R.W., M.M., J.P. and A.H.; software, R.W.; validation, A.H.; formal analysis, R.W.; investigation, R.W.; resources, J.P.; data curation, M.M., Y.C., L.Y. and P.R.; writing-original draft preparation, R.W., Y.C. and M.M.; writing-review and editing, M.M.; visualization, J.P. and R.W.; supervision, M.M., P.K. and D.C.; project administration, M.M.; funding acquisition, M.M. and D.C. All authors have read and agreed to the published version of the manuscript.

Funding: This research was funded by Direction Générale pour l'Armement Français and Gordien Strato. ICON is supported by NASA's Explorers Program through contracts NNG12FA45C and NNG12FA42I.

Acknowledgments: This project would not have been possible without the support of Alexandre Halnaut and Florence Gay (DGA). We are grateful for the contributions in electronics, data acquisition, and real-time data reduction software to Christian Laqui, Frederic Keckhut (GS) and Bernard Stein and Bernd Mielke (Licel GmbH).

Conflicts of Interest: The authors declare no conflict of interest.

\section{References}

1. Bodilis, A. Le bâtiment d'essais et de mesures Monge. REE. Rev. L'électricité L'électronique 2001, 1, 84-89. [CrossRef]

2. Fritts, D.C.; Alexander, M.J. Gravity wave dynamics and effects in the middle atmosphere. Rev. Geophys. 2003, 41. [CrossRef]

3. Hines, C.O. Internal atmospheric gravity waves at ionospheric heights. Can. J. Phys. 1960, 38, 1441-1481. [CrossRef]

4. Lindzen, R.S. Turbulence and stress owing to gravity wave and tidal breakdown. J. Geophys. Res. Ocean. 1981, 86, 9707-9714. [CrossRef]

5. Holton, J.R. The role of gravity wave induced drag and diffusion in the momentum budget of the mesosphere. J. Atmos. Sci. 1982, 39, 791-799. [CrossRef]

6. Fritts, D.C. Gravity wave saturation in the middle atmosphere: A review of theory and observations. Rev. Geophys. 1984, 22, 275-308. [CrossRef] 
7. Garcia, R.R.; Solomon, S. The effect of breaking gravity waves on the dynamics and chemical composition of the mesosphere and lower thermosphere. J. Geophys. Res. Atmos. 1985, 90, 3850-3868. [CrossRef]

8. Snively, J.B.; Pasko, V.P. Breaking of thunderstorm-generated gravity waves as a source of short-period ducted waves at mesopause altitudes. Geophys. Res. Lett. 2003, 30. [CrossRef]

9. Isler, J.R.; Taylor, M.J.; Fritts, D.C. Observational evidence of wave ducting and evanescence in the mesosphere. J. Geophys. Res. Atmos. 1997, 102, 26301-26313. [CrossRef]

10. Fritts, D.C.; Blanchard, R.C.; Coy, L. Gravity wave structure between 60 and $90 \mathrm{~km}$ inferred from space shuttle reentry data. J. Atmos. Sci. 1989, 46, 423-434. [CrossRef]

11. Hauchecorne, A.; Chanin, M.L.; Wilson, R. Mesospheric temperature inversion and gravity wave breaking. Geophys. Res. Lett. 1987, 14, 933-936. [CrossRef]

12. Wilson, R.; Chanin, M.; Hauchecorne, A. Gravity waves in the middle atmosphere observed by Rayleigh lidar: 1 . Case studies. J. Geophys. Res. Atmos. 1991, 96, 5153-5167. [CrossRef]

13. Wilson, R.; Chanin, M.; Hauchecorne, A. Gravity waves in the middle atmosphere observed by Rayleigh lidar: 2 . Climatology. J. Geophys. Res. Atmos. 1991, 96, 5169-5183. [CrossRef]

14. Whiteway, J.; Duck, T.; Donovan, D.P.; Bird, J.; Pal, S.; Carswell, A. Measurements of gravity wave activity within and around the Arctic stratospheric vortex. Geophys. Res. Lett. 1997, 24, 1387-1390. [CrossRef]

15. Sica, R.; Thayaparan, T.; Argall, P.; Russell, A.; Hocking, W. Modulation of upper mesospheric temperature inversions due to tidal-gravity wave interactions. J. Atmos. Sol.-Terr. Phys. 2002, 64, 915-922. [CrossRef]

16. Rauthe, M.; Gerding, M.; Höffner, J.; Lübken, F.J. Lidar temperature measurements of gravity waves over Kühlungsborn (54 N) from 1 to $105 \mathrm{~km}$ : A winter-summer comparison. J. Geophys. Res. Atmos. 2006, 111. [CrossRef]

17. Chu, X.; Yu, Z.; Gardner, C.S.; Chen, C.; Fong, W. Lidar observations of neutral Fe layers and fast gravity waves in the thermosphere (110-155 km) at McMurdo (77.8 S, 166.7 E), Antarctica. Geophys. Res. Lett. 2011, 38. [CrossRef]

18. Ehard, B.; Kaifler, B.; Kaifler, N.; Rapp, M. Evaluation of methods for gravity wave extraction from middle-atmospheric lidar temperature measurements. Atmos. Meas. Tech. 2015, 8, 4645-4655. [CrossRef]

19. Baumgarten, K.; Gerding, M.; Lübken, F.J. Seasonal variation of gravity wave parameters using different filter methods with daylight lidar measurements at midlatitudes. J. Geophys. Res. Atmos. 2017, 122, 2683-2695. [CrossRef]

20. Triplett, C.C.; Collins, R.L.; Nielsen, K.; Harvey, V.L.; Mizutani, K. Role of wind filtering and unbalanced flow generation in middle atmosphere gravity wave activity at Chatanika Alaska. Atmosphere 2017, 8, 27. [CrossRef]

21. Triplett, C.C.; Li, J.; Collins, R.L.; Lehmacher, G.A.; Barjatya, A.; Fritts, D.C.; Strelnikov, B.; Lübken, F.J.; Thurairajah, B.; Harvey, V.L.; et al. Observations of reduced turbulence and wave activity in the Arctic middle atmosphere following the January 2015 sudden stratospheric warming. J. Geophys. Res. Atmos. 2018, 123, 13-259. [CrossRef]

22. Taylor, M.J.; Turnbull, D.; Lowe, R. Spectrometric and imaging measurements of a spectacular gravity wave event observed during the ALOHA-93 campaign. Geophys. Res. Lett. 1995, 22, 2849-2852. [CrossRef]

23. Sedlak, R.; Hannawald, P.; Schmidt, C.; Wüst, S.; Bittner, M.; Stanič, S. Gravity wave instability structures and turbulence from more than one and a half years of $\mathrm{OH}^{*}$ airglow imager observations in Slovenia. Atmos. Meas. Tech. Discuss. 2021, 2021, 1-28. [CrossRef]

24. Fritts, D.C.; Wang, L.; Werne, J.; Lund, T.; Wan, K. Gravity wave instability dynamics at high Reynolds numbers. Part I: Wave field evolution at large amplitudes and high frequencies. J. Atmos. Sci. 2009, 66, 1126-1148. [CrossRef]

25. Fritts, D.C.; Wang, L.; Werne, J.; Lund, T.; Wan, K. Gravity wave instability dynamics at high Reynolds numbers. Part II: Turbulence evolution, structure, and anisotropy. J. Atmos. Sci. 2009, 66, 1149-1171. [CrossRef]

26. Meriwether, J.W.; Gardner, C.S. A review of the mesosphere inversion layer phenomenon. J. Geophys. Res. Atmos. 2000, 105, 12405-12416. [CrossRef]

27. Schmidlin, F. Temperature inversions near $75 \mathrm{~km}$. Geophys. Res. Lett. 1976, 3, 173-176. [CrossRef]

28. Salby, M.; Sassi, F.; Callaghan, P.; Wu, D.; Keckhut, P.; Hauchecorne, A. Mesospheric inversions and their relationship to planetary wave structure. J. Geophys. Res. Atmos. 2002, 107, ACL-4. [CrossRef]

29. Mertens, C.J.; Mlynczak, M.G.; López-Puertas, M.; Wintersteiner, P.P.; Picard, R.H.; Winick, J.R.; Gordley, L.L.; Russell, J.M. Retrieval of mesospheric and lower thermospheric kinetic temperature from measurements of $\mathrm{CO}_{2} 15 \mu \mathrm{m}$ Earth Limb Emission under non-LTE conditions. Geophys. Res. Lett. 2001, 28, 1391-1394. [CrossRef]

30. Ramesh, K.; Sridharan, S.; Vijaya Bhaskara Rao, S. Causative mechanisms for the occurrence of a triple layered mesospheric inversion event over low latitudes. J. Geophys. Res. Space Phys. 2014, 119, 3930-3943. [CrossRef]

31. Lehmacher, G.; Croskey, C.; Mitchell, J.; Friedrich, M.; Lübken, F.J.; Rapp, M.; Kudeki, E.; Fritts, D. Intense turbulence observed above a mesospheric temperature inversion at equatorial latitude. Geophys. Res. Lett. 2006, 33. [CrossRef]

32. Fechine, J.; Wrasse, C.; Takahashi, H.; Mlynczak, M.; Russell, J. Lower-mesospheric inversion layers over Brazilian equatorial region using TIMED/SABER temperature profiles. Adv. Space Res. 2008, 41, 1447-1453. [CrossRef]

33. Gan, Q.; Zhang, S.D.; Yi, F. TIMED/SABER observations of lower mesospheric inversion layers at low and middle latitudes. J. Geophys. Res. Atmos. 2012, 117. [CrossRef]

34. Siva Kumar, V.; Bhavani Kumar, Y.; Raghunath, K.; Rao, P.; Krishnaiah, M.; Mizutani, K.; Aoki, T.; Yasui, M.; Itabe, T. Lidar measurements of mesospheric temperature inversion at a low latitude. Ann. Geophys. 2001, 19, 1039-1044. [CrossRef] 
35. Leblanc, T.; Hauchecorne, A. Recent observations of mesospheric temperature inversions. J. Geophys. Res. Atmos. 1997, 102, 19471-19482. [CrossRef]

36. McLandress, C.; Ward, W. Tidal/gravity wave interactions and their influence on the large-scale dynamics of the middle atmosphere: Model results. J. Geophys. Res. Atmos. 1994, 99, 8139-8155. [CrossRef]

37. Hedin, A.E.; Biondi, M.; Burnside, R.; Hernandez, G.; Johnson, R.; Killeen, T.; Mazaudier, C.; Meriwether, J.; Salah, J.; Sica, R.; et al. Revised global model of thermosphere winds using satellite and ground-based observations. J. Geophys. Res. Space Phys. 1991, 96, 7657-7688. [CrossRef]

38. Smith, A.K. Longitudinal variations in mesospheric winds: Evidence for gravity wave filtering by planetary waves. J. Atmos. Sci. 1996, 53, 1156-1173. [CrossRef]

39. Sassi, F.; Garcia, R.; Boville, B.; Liu, H. On temperature inversions and the mesospheric surf zone. J. Geophys. Res. Atmos. 2002, 107, ACL-8. [CrossRef]

40. Baumgarten, K.; Gerding, M.; Baumgarten, G.; Lübken, F.J. Temporal variability of tidal and gravity waves during a record long 10-day continuous lidar sounding. Atmos. Chem. Phys. 2018, 18, 371-384. [CrossRef]

41. Wing, R.; Martic, M.; Hauchecorne, A.; Porteneuve, J.; Keckhut, P.; Courcoux, Y.; Yung, L.; Retailleau, P.; Cocuron, D. Atmospheric Density and Temperature Vertical Profile Retrieval for Flight-Tests with a Rayleigh Lidar On-Board the French Advanced Test Range Ship Monge. Atmosphere 2020, 11, 75. [CrossRef]

42. Keckhut, P.; Hauchecorne, A.; Chanin, M. A critical review of the database acquired for the long-term surveillance of the middle atmosphere by the French Rayleigh lidars. J. Atmos. Ocean. Technol. 1993, 10, 850-867. [CrossRef]

43. Keckhut, P.; Chanin, M.L.; Hauchecorne, A. Stratosphere temperature measurement using Raman lidar. Appl. Opt. 1990, 29, 5182-5186. [CrossRef]

44. Faduilhe, D.; Keckhut, P.; Bencherif, H.; Robert, L.; Baldy, S. Stratospheric temperature monitoring using a vibrational Raman lidar Part 1: Aerosols and ozone interferences. J. Environ. Monit. 2005, 7, 357-364. [CrossRef]

45. Hauchecorne, A.; Chanin, M.; Keckhut, P.; Nedeljkovic, D. Lidar monitoring of the temperature in the middle and lower atmosphere. Appl. Phys. B 1992, 55, 29-34. [CrossRef]

46. Immel, T.J.; England, S.; Mende, S.; Heelis, R.; Englert, C.; Edelstein, J.; Frey, H.; Korpela, E.; Taylor, E.; Craig, W.; et al. The ionospheric connection explorer mission: Mission goals and design. Space Sci. Rev. 2018, 214, 1-36. [CrossRef] [PubMed]

47. Englert, C.R.; Harlander, J.M.; Brown, C.M.; Marr, K.D. Spatial heterodyne spectroscopy at the Naval Research Laboratory. Appl. Opt. 2015, 54, F158-F163. [CrossRef] [PubMed]

48. Englert, C.R.; Harlander, J.M.; Brown, C.M.; Marr, K.D.; Miller, I.J.; Stump, J.E.; Hancock, J.; Peterson, J.Q.; Kumler, J.; Morrow, W.H.; et al. Michelson interferometer for global high-resolution thermospheric imaging (MIGHTI): Instrument design and calibration. Space Sci. Rev. 2017, 212, 553-584. [CrossRef] [PubMed]

49. Harding, B.J.; Makela, J.J.; Englert, C.R.; Marr, K.D.; Harlander, J.M.; England, S.L.; Immel, T.J. The MIGHTI wind retrieval algorithm: Description and verification. Space Sci. Rev. 2017, 212, 585-600. [CrossRef] [PubMed]

50. Stevens, M.H.; Englert, C.R.; Harlander, J.M.; England, S.L.; Marr, K.D.; Brown, C.M.; Immel, T.J. Retrieval of lower thermospheric temperatures from $\mathrm{O}_{2}$ A band emission: The MIGHTI experiment on ICON. Space Sci. Rev. 2018, 214, 1-9. [CrossRef]

51. Makela, J.J.; Baughman, M.; Navarro, L.A.; Harding, B.J.; Englert, C.R.; Harlander, J.M.; Marr, K.D.; Benkhaldoun, Z.; Kaab, M.; Immel, T.J. Validation of ICON-MIGHTI Thermospheric Wind Observations: 1. Nighttime Red-Line Ground-Based Fabry-Perot Interferometers. J. Geophys. Res. Space Phys. 2021, 126, e2020JA028726. [CrossRef]

52. Harding, B.J.; Chau, J.L.; He, M.; Englert, C.R.; Harlander, J.M.; Marr, K.D.; Makela, J.J.; Clahsen, M.; Li, G.; Ratnam, M.V.; et al. Validation of ICON-MIGHTI thermospheric wind observations: 2. Green-line comparisons to specular meteor radars. J. Geophys. Res. Space Phys. 2021, 126, e2020JA028947. [CrossRef]

53. Rezac, L.; Jian, Y.; Yue, J.; Russell, J.; Kutepov, A.; Garcia, R.; Walker, K.; Bernath, P. Validation of the global distribution of CO volume mixing ratio in the mesosphere and lower thermosphere from SABER. J. Geophys. Res. 2015, 120, 12067-12081. [CrossRef]

54. Rezac, L.; Kutepov, A.; Russell, J.; Feofilov, A.; Yue, J.; Goldberg, R. Simultaneous retrieval of T(p) and CO; VMR from two-channel non-LTE limb radiances and application to daytime SABER/TIMED measurements. J. Atmos. Sol.-Terr. Phys. 2015, 130-131, 23-42. [CrossRef]

55. Schwartz, M.J.; Lambert, A.; Manney, G.L.; Read, W.G.; Livesey, N.J.; Froidevaux, L.; Ao, C.O.; Bernath, P.F.; Boone, C.D.; Cofield, R.E.; et al. Validation of the Aura Microwave Limb Sounder temperature and geopotential height measurements. J. Geophys. Res. Atmos. 2008, 113. [CrossRef]

56. Waters, J.W.; Froidevaux, L.; Harwood, R.S.; Jarnot, R.F.; Pickett, H.M.; Read, W.G.; Siegel, P.H.; Cofield, R.E.; Filipiak, M.J.; Flower, D.A.; et al. The Earth observing system microwave limb sounder (EOS MLS) on the aura Satellite. IEEE Trans. Geosci. Remote Sens. 2006, 44, 1075-1092. [CrossRef]

57. Hersbach, H.; Bell, B.; Berrisford, P.; Hirahara, S.; Horányi, A.; Muñoz-Sabater, J.; Nicolas, J.; Peubey, C.; Radu, R.; Schepers, D.; et al. The ERA5 global reanalysis. Q. J. R. Meteorol. Soc. 2020, 146, 1999-2049. [CrossRef]

58. Hoffmann, L.; Günther, G.; Li, D.; Stein, O.; Wu, X.; Griessbach, S.; Heng, Y.; Konopka, P.; Müller, R.; Vogel, B.; et al. From ERA-Interim to ERA5: The considerable impact of ECMWF's next-generation reanalysis on Lagrangian transport simulations. Atmos. Chem. Phys. 2019, 19, 3097-3124. [CrossRef] 
59. Marlton, G.; Charlton-Perez, A.; Harrison, G.; Polichtchouk, I.; Hauchecorne, A.; Keckhut, P.; Wing, R.; Leblanc, T.; Steinbrecht, W. Using a network of temperature lidars to identify temperature biases in the upper stratosphere in ECMWF reanalyses. Atmos. Chem. Phys. 2021, 21, 6079-6092. [CrossRef]

60. Wing, R.; Hauchecorne, A.; Keckhut, P.; Godin-Beekmann, S.; Khaykin, S.; McCullough, E.M.; Mariscal, J.F.; d'Almeida, E. Lidar temperature series in the middle atmosphere as a reference data set-Part 1: Improved retrievals and a 20-year cross-validation of two co-located French lidars. Atmos. Meas. Tech. 2018, 11, 5531-5547. [CrossRef]

61. Picone, J.M.; Hedin, A.E.; Drob, D.P.; Aikin, A.C. NRLMSISE-00 empirical model of the atmosphere: Statistical comparisons and scientific issues. J. Geophys. Res. Space Phys. 2002, 107,

62. Hauchecorne, A.; Chanin, M.L. Density and temperature profiles obtained by lidar between 35 and $70 \mathrm{~km}$. Geophys. Res. Lett. 1980, 7, 565-568.

63. Khanna, J.; Bandoro, J.; Sica, R.J.; McElroy, C.T. New technique for retrieval of atmospheric temperature profiles from Rayleighscatter lidar measurements using nonlinear inversion. Appl. Opt. 2012, 51, 7945-7952. [CrossRef] [PubMed]

64. Leblanc, T.; Sica, R.J.; van Gijsel, J.A.E.; Godin-Beekmann, S.; Haefele, A.; Trickl, T.; Payen, G.; Gabarrot, F. Proposed standardized definitions for vertical resolution and uncertainty in the NDACC lidar ozone and temperature algorithms - Part 1: Vertical resolution. Atmos. Meas. Tech. 2016, 9, 4029-4049. [CrossRef]

65. Leblanc, T.; Sica, R.J.; van Gijsel, J.A.E.; Haefele, A.; Payen, G.; Liberti, G. Proposed standardized definitions for vertical resolution and uncertainty in the NDACC lidar ozone and temperature algorithms-Part 3: Temperature uncertainty budget. Atmos. Meas. Tech. 2016, 9, 4079-4101. [CrossRef]

66. Iarlori, M.; Madonna, F.; Rizi, V.; Trickl, T.; Amodeo, A. Effective resolution concepts for lidar observations. Atmos. Meas. Tech. 2015, 8, 5157-5176. [CrossRef]

67. Godin, S.; Carswell, A.I.; Donovan, D.P.; Claude, H.; Steinbrecht, W.; McDermid, I.S.; McGee, T.J.; Gross, M.R.; Nakane, H.; Swart, D.P.; et al. Ozone differential absorption lidar algorithm intercomparison. Appl. Opt. 1999, 38, 6225-6236. [CrossRef] [PubMed]

68. Savitzky, A.; Golay, M.J. Smoothing and differentiation of data by simplified least squares procedures. Anal. Chem. 1964, 36, 1627-1639. [CrossRef]

69. Torrence, C.; Compo, G.P. A practical guide to wavelet analysis. Bull. Am. Meteorol. Soc. 1998, 79, 61-78. [CrossRef]

70. Whiteway, J.A.; Carswell, A.I. Lidar observations of gravity wave activity in the upper stratosphere over Toronto. J. Geophys. Res. Atmos. 1995, 100, 14113-14124. [CrossRef]

71. Hagan, M.; Forbes, J.M. Migrating and nonmigrating semidiurnal tides in the upper atmosphere excited by tropospheric latent heat release. J. Geophys. Res. Space Phys. 2003, 108. [CrossRef]

72. Sica, R.; Russell, A. How many waves are in the gravity wave spectrum? Geophys. Res. Lett. 1999, 26, 3617-3620. [CrossRef] 